NBER WORKING PAPER SERIES

\title{
EXPOSURE, EXPERIENCE, AND EXPERTISE: WHY PERSONAL HISTORIES MATTER IN ECONOMICS
}

\author{
Ulrike Malmendier \\ Working Paper 29336 \\ http://www.nber.org/papers/w29336 \\ NATIONAL BUREAU OF ECONOMIC RESEARCH \\ 1050 Massachusetts Avenue \\ Cambridge, MA 02138 \\ October 2021
}

This article is based on the JEEA-FBBVA Lecture of the European Economic Association given at the 2020 ASSA meeting in San Diego and in November 2020 at FBBVA in Madrid, titled "Experience, Bias, and Expertise -- How Experience Effects Bias Decision-Making Even Among Experts." I thank the audiences for their comments and suggestions, and Clint Hamilton, Karin $\mathrm{Li}$, and Junru Lyu for excellent research assistance. The views expressed herein are those of the author and do not necessarily reflect the views of the National Bureau of Economic Research.

NBER working papers are circulated for discussion and comment purposes. They have not been peer-reviewed or been subject to the review by the NBER Board of Directors that accompanies official NBER publications.

(C) 2021 by Ulrike Malmendier. All rights reserved. Short sections of text, not to exceed two paragraphs, may be quoted without explicit permission provided that full credit, including () notice, is given to the source. 
Exposure, Experience, and Expertise: Why Personal Histories Matter in Economics

Ulrike Malmendier

NBER Working Paper No. 29336

October 2021

JEL No. E7,G11,G12,G41

\begin{abstract}
$\underline{\text { ABSTRACT }}$
Personal experiences of economic outcomes, from global financial crises to individual-level job losses, can shape individual beliefs, risk attitudes, and choices for years to come. A growing literature on experience effects shows that individuals act as if past outcomes that they experienced were overly likely to occur again, even if they are fully informed about the actual likelihood. This reaction to past experiences is long-lasting though it decays over time as individuals accumulate new experiences. Modern brain science helps understand these processes. Evidence on neuroplasticity reveals that personal experiences and learning alter the strength of neural connections and fine-tune the brain structure to those past experiences ("use-dependent brain"). I show that experience effects help understand belief formation and decision-making in a wide area of economic applications, including inflation, home purchases, mortgage choices, and consumption expenditures. I argue that experience-based learning is broadly applicable to economic decision-making and discuss topics for future research in education, health, race, and gender economics.
\end{abstract}

Ulrike Malmendier

Department of Economics

549 Evans Hall \# 3880

University of California, Berkeley

Berkeley, CA 94720-3880

and NBER

ulrike@econ.berkeley.edu 


\section{Introduction}

In early 2020, shortly after I delivered the JEEA-FBBVA Lecture of the European Economic Association, which this article is based upon, COVID-19 started to upend almost every aspect of people's lives. The pandemic spread across the globe, killed millions of people, and infected hundreds of millions. Even for those who were lucky enough to avoid infection, life began to look very different. Most workplaces were closed, and people started working from home. Essential workers still showed up at their workplaces - the hospitals, the grocery stores, the delivery service sites - but did so in masks and PPE, and under very different workplace rules. Schools were closed, relegating even kindergartners to "distance learning," and driving many children, teachers, and parents to despair.

Most of these challenges were expected to be time-limited. Once the health risks would subside and our schedules and support systems resumed, we would return to a pre-pandemic way of living - or so we thought. An yet, despite these expectations, there were early signs that this pandemic experience might leave its mark on us in the long run. Parents under the double-pressure of working from home and co-teaching their kids for 18 months made career changes that would last beyond the pandemic. Staff at universities and firms refused to give up working from home, even when everybody was vaccinated and infections were not the concern. These types of observations raise the question: Would people behave differently post-COVID even if all economic determinants, from health conditions to childcare and workplace settings, were restored to the pre-COVID world? Did the experience alter us?

It is needless to say that the post-pandemic world is different from the pre-pandemic world, and that these differences explain many changes in behavior. For example, a simple economic explanation for continued teleworking could be that the pandemic forced businesses and workers to incur the initial set-up cost, learn how to navigate new online platforms, and adjust work schedules and processes. Other decisions are harder to pin 
to changed circumstances. The JOLTS database of the U.S. Bureau of Labor Statistics (BLS) reveals that the number of Americans voluntarily quitting their jobs reached a record high in Spring 2021, ${ }^{2}$ a phenomenon that news outlets have called "The Great Resignation." Quits are generally pro-cyclical, but the pandemic appears to have changed that pattern. So, to refine our question from above: did living through the pandemic alter us in the longer-run, beyond the explanatory power of changed financial and other personal circumstances and beyond the arrival of new information?

The growing research on experience effects implies that the answer is yes - that there will be long-term changes in beliefs and behavior even "ceteris paribus," even if we were actually back to a world pre-Covid-19. The term experience effects was coined to describe the empirical finding that individuals living through and personally experiencing the realizations of macro, finance, and other economic processes respond to these experiences differently from people who are fully informed about the same outcomes, but did not personally experience them. This literature has found that personal experiences are significantly more powerful in shaping risk attitudes, beliefs, and decision-making than "information."

The purpose of this article is to lay out why and where such persistent experience-based changes occur and to illustrate the broad applicability of the underlying mechanisms in a wide area of fields. It also emphasizes the fundamental change in our thinking about belief formation and decision-making that is needed in economics to accommodate the role of individuals' past in their present decision-making.

In Section 2, I start from contrasting the notion of "learning" and "information acquisition" in economics with the neuroscientific understanding of brain functioning and brain architecture. Past experiences have been shown to re-wire the brain, and such a "use-dependent" brain (Perry et al., 1995) naturally gives rise to experience-dependent

\footnotetext{
${ }^{2}$ https://www.bls.gov/news.release/jolts.t04.htm
} 
behavior, above and beyond the influence of information and economic determinants.

I then turn to the existing evidence on the influence of experience-based learning on economic decision-making (Section 3). Much of the initial evidence on experience effects came from finance, in particular the stock market. In fact, the concept of "experience effects" was first developed in Malmendier and Nagel (2011)'s work on Depression Babies and the influence of past stock-market realizations on stock-market participation. ${ }^{3}$ In this article, however, I aim to demonstrate the broad applicability of experience-based learning to all types of economic (and non-economic) decisions outside of finance.

Specifically, I survey some of the existing evidence on experience effects in the formation of inflation expectations, mortgage choice, tenure decisions, and consumption decisions. These studies discussed in Section 3 show that the concept of "re-wiring" through personal experiences helps us to understand why different generations differ in their beliefs and attitudes, but also why and how these differences change over time. Prior theoretical and empirical work has identified age and life-cycle determinants as well as the influence of current savings, borrowing, and similar economic determinants. The literature on experience effects reaches further. The promise is that, once we integrate a role of "the past" into our model, we will be able to provide some understanding of how economic and political crises can shape entire generations to behave differently from other generations, and how these differences evolve over time.

In Section 4, I synthesize some of the key features of experience effects observed in those empirical studies. First, experience effects are long-lasting. Past experiences can alter people - their beliefs, their risk attitudes, and their decision-making - for decades to come. These effects are not immutable, though, as new experiences are made and exert

\footnotetext{
${ }^{3}$ Early work by Kaustia and Knüpfer (2008) has shown that the personal experience of returns in Initial Public Offerings plays an important role in the pattern of future IPO subscriptions. This and other finance work is surveyed in Malmendier (2021), where I also identify the four key empirical features of how past experiences influence decision-making, which I refer to in this article.
} 
new influences. In fact, the second characteristic of experience effects is their embedded recency bias: the most recent experiences obtain the most weight in the experiencebased belief formation of individuals. Third, experience effects are highly domain specific, meaning that the brain records the type of stimuli connected to the specific experience, including visual and sensory stimuli, rather than the abstract underlying stochastic process. Hence, experiences in one setting (say, the stock market) affect beliefs and future risk-taking specifically in that setting (stock investment), but not necessarily in related settings, such as other asset markets (e.g. the bond market), even if the realizations of the underlying stochastic processes are correlated. And fourth, experience effects are not simply an updating mistake that would only affect the uninformed. Even those who are highly informed about and even specialized in a domain of knowledge tend to respond to their personal past experiences. Personal exposure to events and outcomes "re-wires" our brains, regardless of whether we are experts or not. ${ }^{4}$ I discuss which of these four features are captured in related models of memory, retrieval, and attention, and how those approaches relate to experience-based learning.

In Section 5, I then turn to other plausible applications in fields where experience-based learning has not yet been explored. These include topics in labor economics, gender, education, and health. Section 6 concludes.

\footnotetext{
${ }^{4}$ In the context of the COVID-19 pandemic, the infectious disease researcher John Barry from Tulane University, whose book about the 1918 Spanish Influenza pandemic had reemerged as a best seller in 2020, described this notion when asked about his experience of living through the COVID-19 pandemic and whether he had expected to witness a pandemic like this when he wrote the book. His answer was: "Yes and no. I think anybody who understands anything about infectious disease recognized that we were going to, sooner or later, face something like this; ... . But, intellectually understanding it, is one thing, and having it hit you is something quite different. So, I am like everyone else in that sense." ${ }^{5}$ In other words, even Barry was shaken and "hit" by this pandemic experience, and no scientific knowledge ("information") could prepare him. He felt "like everyone else" despite knowing the science of respiratory disease epidemics, knowing the likelihood of their emergence, and knowing the effects on humanity. Intellectually understanding - having the information - is one thing. "Having it hit you is something quite different," even for highly trained, well informed professionals.
} 


\section{Learning, Information, and Brain Plasticity}

The traditional notion of learning and belief formation in economics relies on informationbased updating. If a piece of information reaches an individual, the individual takes it into account - either in an unbiased or a biased manner - and updates beliefs. If information is not incorporated, that failure is assumed to reflect informational asymmetries. In fact, a large part of the literature on moral hazard and adverse selection addresses the implications of precisely those informational asymmetries. More recent behavioral theories also allow for cognitive limitations, limited attention and other biases to affect information processing.

But what if information is readily available to an agent, and she knows how to process the information, but still does not incorporate it rationally? The empirical literature on experience effects claims that past experiences can induce such behavior. For example, investors might know and understand the value of diversified stock-market investment; but, after getting burned in the stock market in the past, they keep all their savings in fixed-interest vehicles. In fact, the Great Depression created an entire generation that persistently shied away from stock-market investment for that reason (Malmendier and Nagel, 2011). This is precisely the type of scenario in which we can see the power of past experiences at work. Broadly speaking, individuals act in a way that, ex post, would have been beneficial in the past (no investment in stocks on Black Tuesday, October 29. 1929) even if they know it not to be optimal right now, nor in general.

It turns out that such behavior is not surprising to brain scientists. On the most fundamental level, the discrepancy between typical economic models of learning and actual brain functioning is that, in the brain, learning something new manifests itself in changes to the architecture of this complex network of neurons. It can either be a structural change, or a change in the efficiency of an existing connection, but it is a change to the brain's "hardware." That is, while we economists tend to attribute flawed output (such 
as the over-weighting of personal experiences) to flawed input (information asymmetries) or faulty processing software (biased instructions on how to use the information), brain science tells us that it is also the hardware (brain architecture), which has been finetuned to respond to those past scenarios. As Perry et al. (1995) put it, the brain exhibits "use-dependent" development so that "states become traits."

The umbrella term for those structural changes to the brain is neural plasticity. This can occur in many different ways. An extreme example is that a part of the brain associated with a specific function can grow extraordinarily large, often in response to a loss of another ability. For example, blind people may have a visual cortex that is better functionally connected to other parts of the brain (Burton et al., 2014). In response to their high reliance on tactile and other sensory modalities of information, the neurons in the visual cortex are repurposed to other parts of the brain to assist in their function. This compensatory process to assist blind people is experientially motivated.

Even without the loss of another function, the brain specializes and devotes more resources to what an individual devotes more resources to in real life. For example, the sensorimotor parts of the brain, which coordinate movement, are often found to be larger in musicians who spend long hours of practice with a musical instrument such as a piano that requires fine motor control (Gärtner et al., 2013). Another famous example are London cab drivers, who have been found to have enlarged hippocampi, i.e., the brain region important for spatial navigation (Maguire et al., 2006).

Related to our motivating examples of crisis experiences, recent experimental findings show that a neural population that usually encodes rewards can start encoding adverse events (Sharpe et al., 2021). In that way, past experiences shape the neural circuits recruited for future learning in a highly specific manner, implying that prior experiences might affect the process of learning in and of itself.

The type of neuroplasticity most related to experience effects is likely the strengthening 
(or weakening) of existing synaptic connections. The human brain consists of billions of neurons, linked via synapses. These neurons communicate via small bursts of electrical energy (action potentials) that are set off by stimuli. ${ }^{6}$ How and how often we make an experience predicts the strength and shape of synapse formation, as first discovered by Bliss and Lømo (1973). When the firing (pre-synaptic) neuron repeatedly sends out signals, the number of receptors of the post-synaptic neuron increase. That is, repeated or prolonged exposure makes it more likely that even a weak stimulation afterwards can find its way through the membrane of the post-synaptic neuron. The long-lasting enhancement in signal transmission between two neurons after repeated stimulation is known as long-term potentiation (LTP), and it is today the dominant cellular model underpinning of memory in the mammalian brain.

Later research has distinguished between shorter- and longer-lasting (late) LTP, where the latter is of interest here in order to understand longer-lasting experience effects. Frey and Morris (1997) first proposed a role for "synaptic tags" at the potentiated synapses that allow to establish late LTP. The synaptic tagging hypothesis states that synapses get 'tagged' by some previous synaptic activity, e. g., a post-synaptically localized protein whose function, when the synapse is activated, is to stabilize recently induced temporary changes in synaptic efficacy. In other words, those temporary changes are extended in terms of their persistence (Frey and Morris, 1998).

One variant of this neuroscientific concept is of particular interest for our rethinking of learning, namely, the concept of 'emotional tagging.' When we economists model learning and information retrieval we typically pay little attention to the role of emotions. However, building on an older literature on mood congruence and state dependence in the 1970s and 1980s, e.g., Weingartner et al. (1977), Isen et al. (1978), Blaney (1986), modern neurological foundations of mood and memory show that emotionally arousing events are

\footnotetext{
${ }^{6}$ See, e.g., chapter 5 in Bear et al. (2020) for a textbook discussion.
} 
remembered better. A key role is assigned to the amygdala, one of the oldest parts of our brain, which is also called the limbic brain (Dolan, 2002; Richter-Levin and Akirav, 2003; LaBar and Cabeza, 2006). Since the emotional arousal created by stimuli are processed in the amygdala and affect memory, the amygdala and at least the hippocampus, if not other parts of the brain, appear to interact.

Consider the day I am writing these words, during a stay in Tuscany on the morning after Italy won the soccer Eurocup for only the second time in history. As joyful as watching those celebrations was, I fear that, 10 years out, I will not remember. But I am willing to bet that many of Italians who were celebrating will remember for years to come which country won that COVID-delayed Eurocup in 2021. More generally, we can all recall details and moments when we felt extremely happy or surprised, like a surprise party or high school graduation. Similarly, we vividly remember some of the saddest moments of our lives like the loss of a loved one. What these examples have in common is that the experiences involved are associated with strong emotions, which help us remember them better. We may not remember what we ate for lunch last Tuesday, but definitely remember going out with friends for dinner that same Tuesday night.

Our little detour into 'emotional tagging' highlights the distinction we started from in this section - the role of stimuli versus information. Data provision might stimulate the brain and induce the firing of neurotransmitters, but aspects beyond the informational content traditionally considered in economics - such as the tone of voice or facial expression of the information providers - are likely to be powerful and possibly even override the abstract informational content. In other words, we might want to reframe belief formation and choice behavior as a function of stimulus input, rather than (only) informational input.

This reframing, in turn, gives rise to the idea of 'domain-specific' processing. We can think of the brain's processing modules receiving only a certain type or a certain range of 
information ("input specificity" or "central specificity", cf. Spunt and Adolphs (2017)). Note that the term domain specificity has been used in the sciences for decades, with varying meaning. It is often associated with the philosopher and cognitive scientist Fodor and his monograph on "The Modularity of Mind" (Fodor, 1983). Fodor conceptualized the work of our minds as information-processing modules that work rather independently from each other and are responsible for distinct processes such as linguistic or perceptual processes. The concept of modules, in turn, goes back to brain scientists observing specific deficits and remaining capabilities in brain-damaged patients, and concluding that we can divide the brain into separate modules, or cognitive domains, responsible for, say, number processing, face processing, grammar, space, etc. While these sharp distinctions into domains are now generally viewed as oversimplifications (cf. KarmiloffSmith (2015)), the literature and findings do provide us with the concept of a domain that can be specified in terms of stimulus input.

Circling back to experience effects, we can now see that the neuroscience background allows us to understand several relevant concepts. First, the brain is extremely sensitive to our experiences, and the effects of what we do and encounter can range from small molecular-level changes all the way to large structural reorganization of the brain (cf. Doidge (2007)). Second, the impact of past experiences persists in the long-run if it was strong enough or is reinforced via repeated exposure. Third, the depth of the emotions felt at the time of the experience are a natural candidate for explaining the differences betweeen more or less anchored memories, and mapping out the spectrum from "only theoretical (or abstract) knowledge" to "firmly anchored and available knowledge."

This background information, in turn, provides the underpinning for the "four key features" of experience effects previewed in the introduction, most directly (1) the longlasting effects of past experiences and also (2) the embedded recency bias, as synapse formation and structural brain changes keep responding to new experiences and the effects 
of older experiences fade and might be undone. We can also see why experiences in one domain (say, the stock market) do not necessarily affect decision-making in a closely related domain (other risky assets), i..e., key feature (3), as the stimuli are different and processed differently in the brain. For example, stock-market news may trigger a connection to fear, given past experiences, but stimuli based on correlated assets or events will not if they are not connected to a prior experience. Hebbian plasticity, i. e., the notion that 'cells that wire together fire together,' is fundamentally different from analytical information processing. Finally, the neuroscience perspective also makes it easier to "digest" key feature (4), namely that even experts who "should know better" are affected by their personal experiences. Experience-based belief formation and risktaking is a hardware issue that affects every mammalian brain.

\section{Empirical Evidence}

We now turn to some of the existing evidence on experience effects in economics, including studies on the formation of inflation expectations, mortgage choice, tenure decisions, and consumption decisions. As these studies show, if we integrate the notion of "re-wiring" through personal experiences, we are able to accommodate both intergenerational differences in beliefs and risk taking, as well as changes therein over time.

\subsection{Daily Price Signals and Beliefs}

The insights about brain functioning that we gleaned from neuroscience in the previous section imply that the real-world processing of "stimuli" does not quite translate into the processing of information as modeled in economics. How information is received, which emotions are felt when it is received, and how often the exposure to information is repeated appear to play important roles, which traditional economic thinking do not capture. 
One study that illustrates some of these discrepancies in the context of consumer behavior is D'Acunto et al. (2021). This study shows that prices and price changes that consumers personally "experience" (i. e., pay for) frequently in daily life have an outsized influence on their perception of current inflation and beliefs about future inflation.

To show this, the authors combine detailed information about the quantity and prices of households' non-durable consumption baskets with new survey data on expectations.

The consumption data is from the Kilts Nielsen Consumer Panel (KNCP), which records the purchases of 1.5 million unique products, including groceries, drugs, small appliances, and electronics, by around 60,000 households from 2004-2018. Nielsen estimates that the KNCP covers 20-25\% of US households' consumption. Households report demographic characteristics in addition to the prices, quantities, and shopping outlets of all items in their consumption bundles.

The expectations data comes from a customized survey that was run on the Kilts Nielsen sample in June 2015 and June 2016. The survey elicited perceived inflation (over the previous 12 months) and expected inflation (over the next 12 months), in terms of both point estimates and the full probability distribution. The fine level of granularity of the data allows to study in detail which price changes are most relevant in shaping inflation expectations, while keeping constant a large range of individual-level characteristics as well as other personal and macroeconomic expectations.

One question in the survey was what sources of information they thought about when asked them about inflation. The nine response options included media (TV/radio, newspapers, online news, social media), other people (family \& friends, colleagues, financial advisors), and of course their own shopping experience. As Figure 1 shows, own shopping is mentioned much more frequently than any form of media, any form of personal communication, and other sources.

The Kilts Nielsen data confirms that this is the case, i. e., that beliefs about inflation 


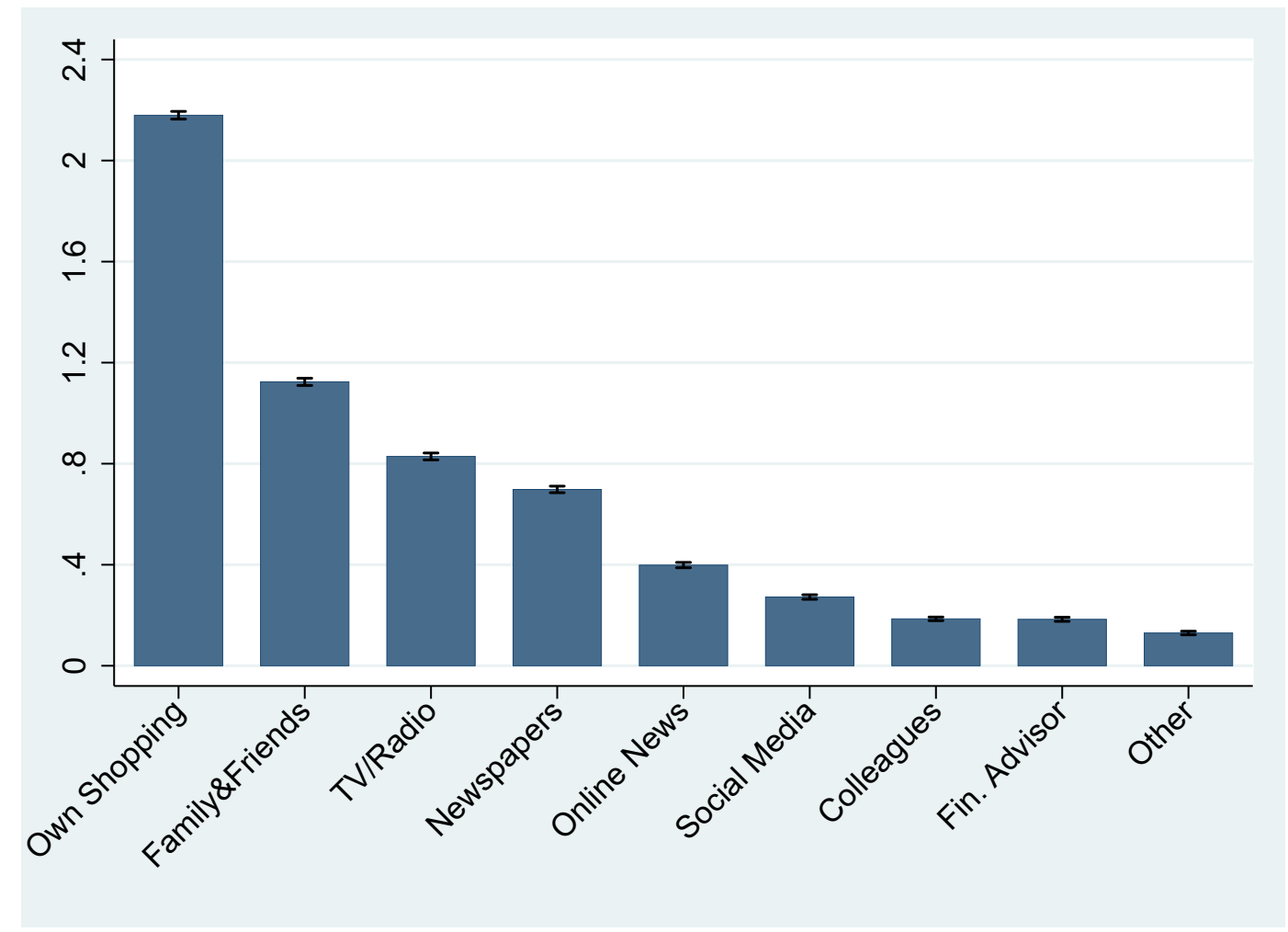

Figure 1: What sources of information do you think about when asked about inflation? The figures shows the average number of mentions for different responses to the question "Thinking about the rate of inflation/deflation, which were the top three sources of information for your answers?", asked in the the Chicago Booth Attitudes and Expectations survey (CBAES) from 2015-2016. Respondents were asked to indicate up to three options from the following (randomized) list: Newspaper \& Magazine; Radio \& Television; Colleagues; Friends \& Family; Financial advisors; Social networking websites; Other websites; Own Shopping experience; and Other (specify).

are highly responsive to the own shopping experience. To measure households' "experienced inflation," the authors construct a chained Laspeyres price index that mirrors the Consumer Price Index (CPI), but uses each household's non-durable consumption basket instead of a representative consumption basket. They use the one-year period starting two years before the respective survey wave as base period and construct individual price changes at the good level using volume-weighted average prices across two years. This Household CPI turns out to be a significant predictor of 12-month-ahead inflation expectations. When grouping households into eight equal-sized bins of Household CPI, as shown in Figure 2, the difference in expected inflation between households in the lowest 


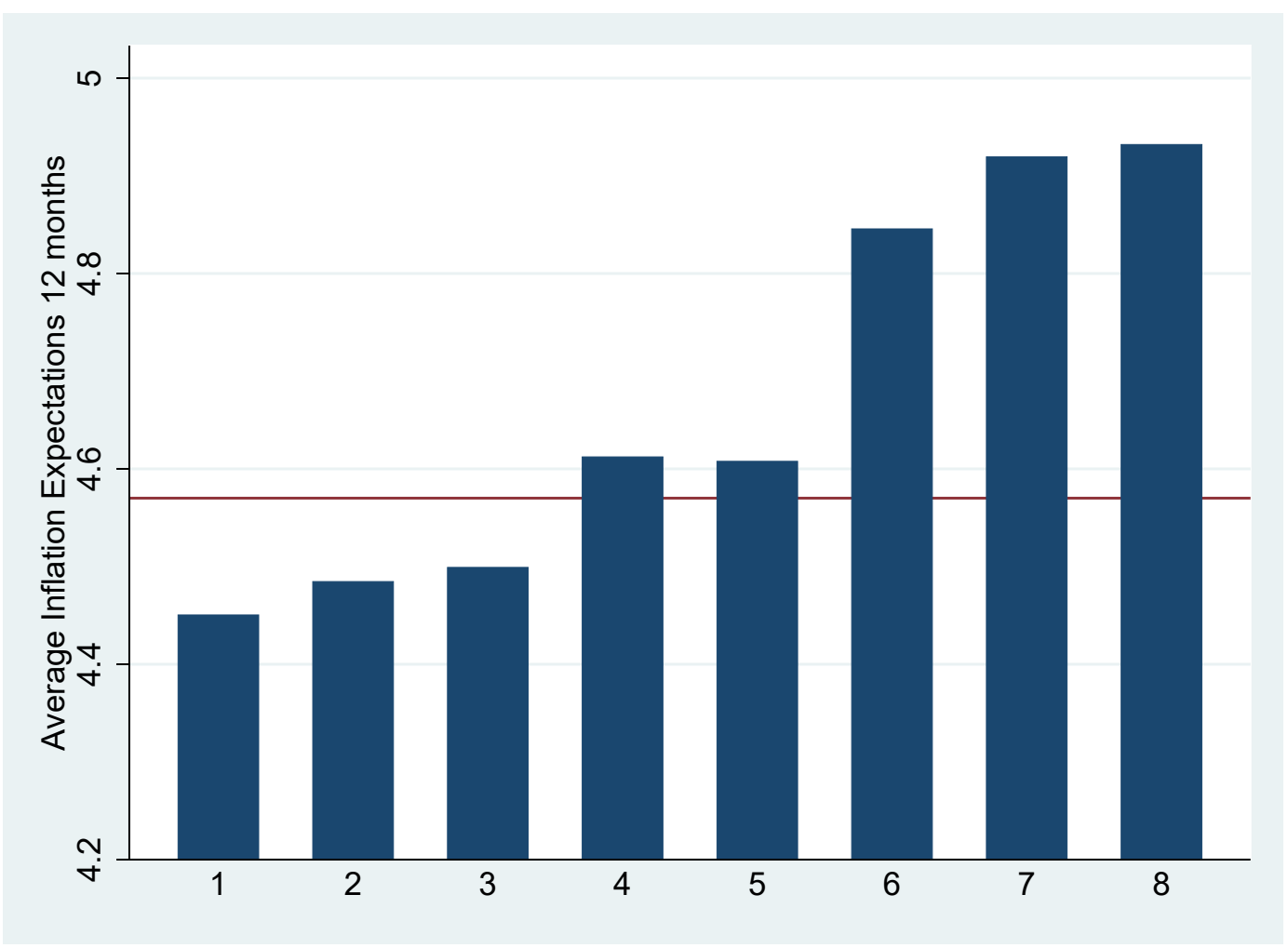

Figure 2: Grocery Shopping and Inflation Expectations. The figure shows the averages of inflation expectations across households in eight equal-sized bins by realized inflation rates in households' consumption bundles (Household CPI). Inflation expectations are from the customized Chicago Booth Attitudes and Expectations survey (CBAES) fielded in 6/2015 and 6/2016. The measures of realized inflation are constructed using micro data from the Kilts-Nielsen Consumer Panel. The Household CPI uses the Nielsen expenditure shares in the base periods as weights.

and highest bin is $0.5 \mathrm{pp}$, which is very large given a realized inflation rate of around $1 \%$ during the same period (and an inflation target of $2 \%$ ). The results hold conditioning on a rich set of demographics including age, income, gender, marital status, household size, education, employment status, and risk tolerance. Other features of price changes such as their volatility, their recency, or sales do not matter, nor do alternative weighting schemes affect the results. The data even allows for within-individual analyses: as a given household's experienced CPI changes across the two survey waves, so do their inflation expectations. Thus, time-invariant individual characteristics, such as cognitive abilities or financial sophistication, cannot explain the findings. 
A couple of additional results warrant mention in the context of identifying underlying mechanisms of belief formation:

First, the results are even stronger when using an alternative measure of households' experienced inflation that uses the frequency of purchase rather than the expenditure share as the weight in the household's consumption basket. If we define

$$
\text { Experienced } C P I_{i, t}=\frac{\sum_{n=1}^{N} \Delta p_{n, i, t} \times \omega_{n, i}}{\sum_{n=1}^{N} \omega_{n, i}},
$$

where $p_{n, i, t}$ is the log price of good $n$ purchased by household $i$ at time $t$, and $\omega_{n, i}$ is the weight of good $n$ in the experienced inflation rate of household $i$, then the aforementioned Household CPI uses $\omega_{n, i}=p_{n, i, 0} \times q_{n, i, 0}$ (expenditure share), and an alternative Frequency $C P I$ sets $\omega_{n, i}=f_{n, i, 0}$, where ${ }_{n, i, 0}$ is the frequency of purchases in some base period.

It turns out that the association of the Frequency CPI with inflation expectations is 20\%-50\% larger than that of the Household CPI. Moreover, if both measures are included in the estimation, the coefficient on the Household CPI shrinks towards 0 and is no longer significant, while the point estimate on the Frequency CPI remains virtually unchanged and statistically significant. In other words, the frequency with which a price stimulus is received appears to carry more weight than its expenditure share. The latter finding is consistent with consumers perceiving the price signals from frequently purchased goods as more precise (Angeletos and Lian, 2016), though the mechanism pointed to here is more akin to Kahneman and Tversky's availability bias (cf. the frequency bias in Georganas et al. (2014)).

Second, the data also reveals that large price changes matter more, possibly because they are more salient or more surprising. Relatedly, less frequent shoppers, who are more likely to observe such larger price changes, tend to respond more strongly to personally experienced price movements.

Third, these findings are not restricted to non-durable consumption goods. While the KILTS Nielsen data does not capture all prices consumers face, our survey confirms that 
other prices can crowd out grocery prices, e.g., gas prices for consumers who often have to refill the tank, or restaurant prices for people who frequent restaurants.

In summary, stimuli arising from prices we pay for in our daily lives affect beliefs about future price changes. In particular, it matters how often a consumer receives the price stimulus (i. e., purchases an item), with less consideration for the item's expenditure share in the consumer's consumption bundle.

\subsection{Long-term Effects of Inflation Experiences on Beliefs}

The study reported above illustrates determinants of belief formation that appear consistent with the neuroscience mechanisms discussed in Section 2. However, the short sample period of the underlying expectations data does not allow to explore longer-lasting effects of such determinants. One data set suitable for identifying the long-run effects of past exposure to inflation is the Michigan Survey of Consumers. Since 1953 the Survey Research Center at the University of Michigan has elicited inflation expectations from a representative sample of US households, amounting to a time series of over 60 years.

The question is how to relate these elicited beliefs to personal inflation experiences of all households in the $M S C$ sample. In order to capture lifetime experiences of even the oldest respondents, we need inflation data stretching back 74 years before the start of the $M S C$ survey data in 1953. While there is no detailed data about personal consumption bundles over a time span, there is long-term historical data on the consumer price index (CPI), available from Robert Shiller's website (see Shiller (2005)).

Malmendier and Nagel (2016) utilize those two data sets to explore the longterm effects of personal inflation exposure. They propose an experience-based learning algorithm similar to the adaptive-learning "rules of thumb" (Marcet and Sargent, 1989), ${ }^{7}$ but with the twist that individuals put more weight on data experienced during their lifetimes

\footnotetext{
${ }^{7}$ See also Bray (1982), Sargent (1993), and Evans and Honkapohja (2001).
} 
than on other historical data. Specifically, individuals use experienced inflation rates to estimate the perceived $\mathrm{AR}(1)$ model of inflation,

$$
\pi_{t+1}=\alpha+\phi \pi_{t}+\eta_{t+1}
$$

recursively. That is, they estimate $b \equiv(\alpha, \phi)^{\prime}$ recursively using

$$
\begin{array}{r}
b_{t, s}=b_{t-1, s}+\gamma_{t, s} R_{t, s}^{-1} x_{t-1}\left(\pi_{t}-b_{t-1, s}^{\prime} x_{t-1}\right) \\
R_{t, s}=R_{t-1, s}+\gamma_{t, s}\left(x_{t-1} x_{t-1}^{\prime}-R_{t-1, s}\right)
\end{array}
$$

where $x_{t} \equiv\left(1, \pi_{t}\right)^{\prime}, s$ is the birth year (and hence $s-t$ age). The key difference to standard adaptive learning models is that the model allows the gain parameter $\gamma_{t, s}$, i. e., the strength of updating in response to surprise inflation, to depend on which realizations an individual has personally experienced over their life so far. Specifically, $\gamma$ depends on age $=t-s$, instead of calendar time $t$,

$$
\gamma_{t, s}= \begin{cases}\frac{\theta}{t-s} & \text { if } t-s \geq \theta \\ 1 & \text { if } t-s<\theta\end{cases}
$$

where $\theta$ determines the degree to which earlier observations are downweighted (and $\gamma_{t, s}=$ 1 is a starting condition that implies that data before birth does not receive experience weights). ${ }^{8}$ The parameterization implies that young individuals (with a smaller $t-s$ ) react more strongly to an inflation surprise than older individuals. And for all ages, it allows experiences earlier and later in life to have a different influence. If the data indicates $\theta=1$, this formulation amounts to equal weighting of all life-time experiences; if the data indicates $\theta>1$, it implies recency bias, as illustrated in Figure 3 for a hypothetical 40-year old person and 60-year old person.

For any $\theta$, the weight placed on the newest observation declines with age. For example

\footnotetext{
${ }^{8}$ Individuals start the recursion at some point in the distant past. As Malmendier and Nagel (2016) point out, the initial conditions do not exert any relevant influence since the empirical parameter estimates of the parameter that determines $\gamma_{t, s}$ implies that past data is downweighted sufficiently fast.
} 

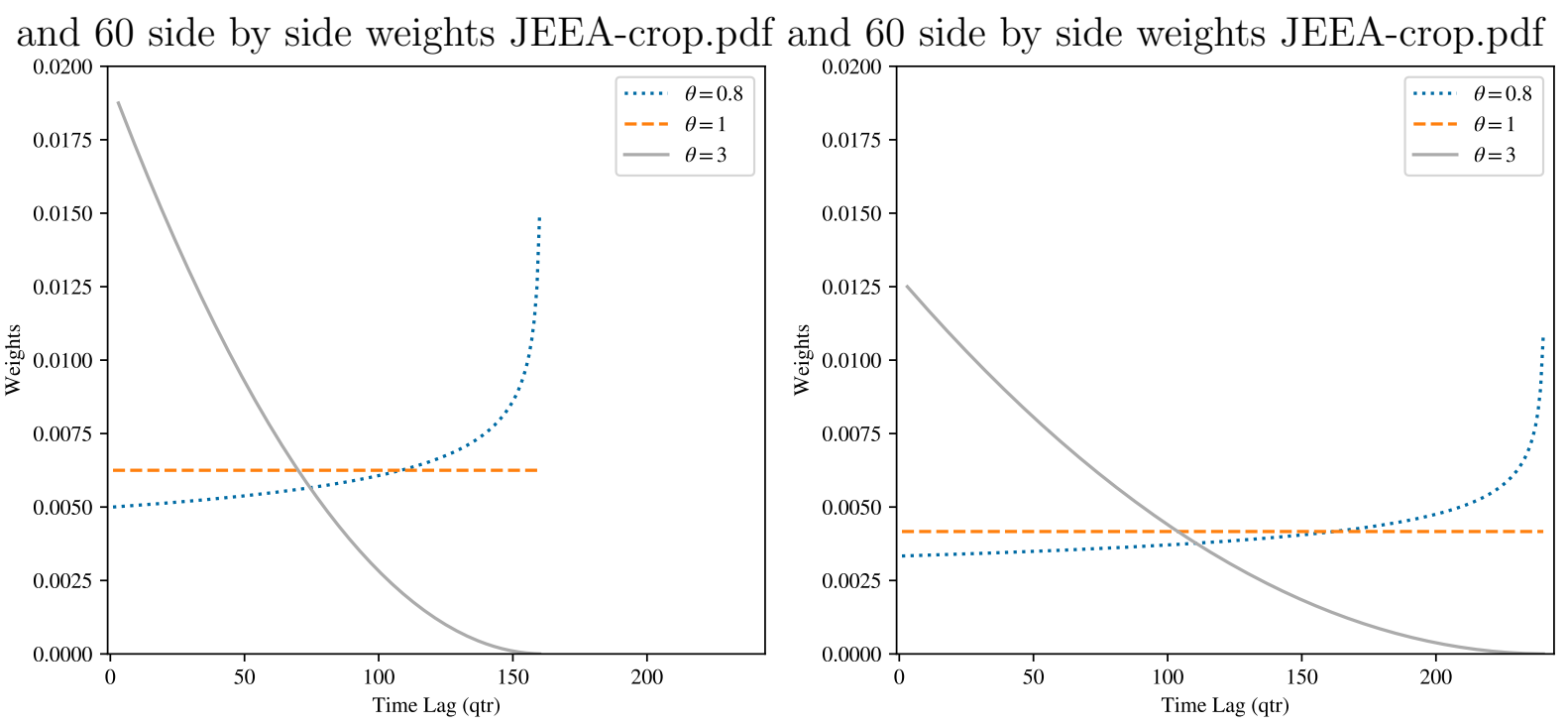

Figure 3: Implied weighting of experienced data for two ages. The figure shows the implied weights on past inflation rates for a 40-year (160 qtr.) old individual on the left and a 60-year (240 qtr.) old individual for different values of $\theta$.

with $\theta=1$, a 40 -year old places a weight of about .006 on the newest observation, but a 6-year old places only a weight of about .004 on the newest observation. This is sensible in the context of learning from experience: Young individuals, who have experienced only a small set of historical data, place a higher weight on new information than older individuals. This means recent events have a stronger marginal influence on expectations. As an example, young individuals react more strongly to an inflation surprise than older individuals who already have a longer data series accumulated in their lifetime histories.

As we can also see, this formulation implies that different generations can disagree about the outlook for inflation as their different past experiences lead them to form different beliefs. Moreover, their beliefs do not converge. Instead, there is perpetual disagreement as the weights on historical realizations diminishes over time as older generations exit the market and young generations enter.

Empirically, Malmendier and Nagel (2016) allow not only past experiences but also other influences to affect beliefs, including a "common component" that reflects the in- 
fluence of, say, the media, the opinions of professional forecasters, and even of all available historical data. The estimation includes time dummies that absorb all such influences:

$$
\tilde{\pi}_{t+1 \mid t, s}=\beta \tau_{t+1 \mid t, s}+\delta^{\prime} D_{t}+\varepsilon_{t, s}
$$

where $\tilde{\pi}_{t+1 \mid t, s}$ denotes measured inflation expectations from survey data, $\tau_{t+1 \mid t, s}$ is the learning-from-experience component, and $D_{t}$ a vector of time dummies. The disturbance $\varepsilon_{t, s}$ is assumed to be uncorrelated with $\tau_{t+1 \mid t, s}$, but allowed to be correlated over time within birth-year cohorts and between cohorts within the same time period. It captures, for example, measurement error in the survey data and idiosyncratic factors influencing expectations beyond those explicitly considered here. They use model (1)-(5) to jointly estimate $\theta$ and $\beta$ with non-linear least squares. (Recall that $\tau_{t+1 \mid t, s}$ is a non-linear function of $\theta$.)

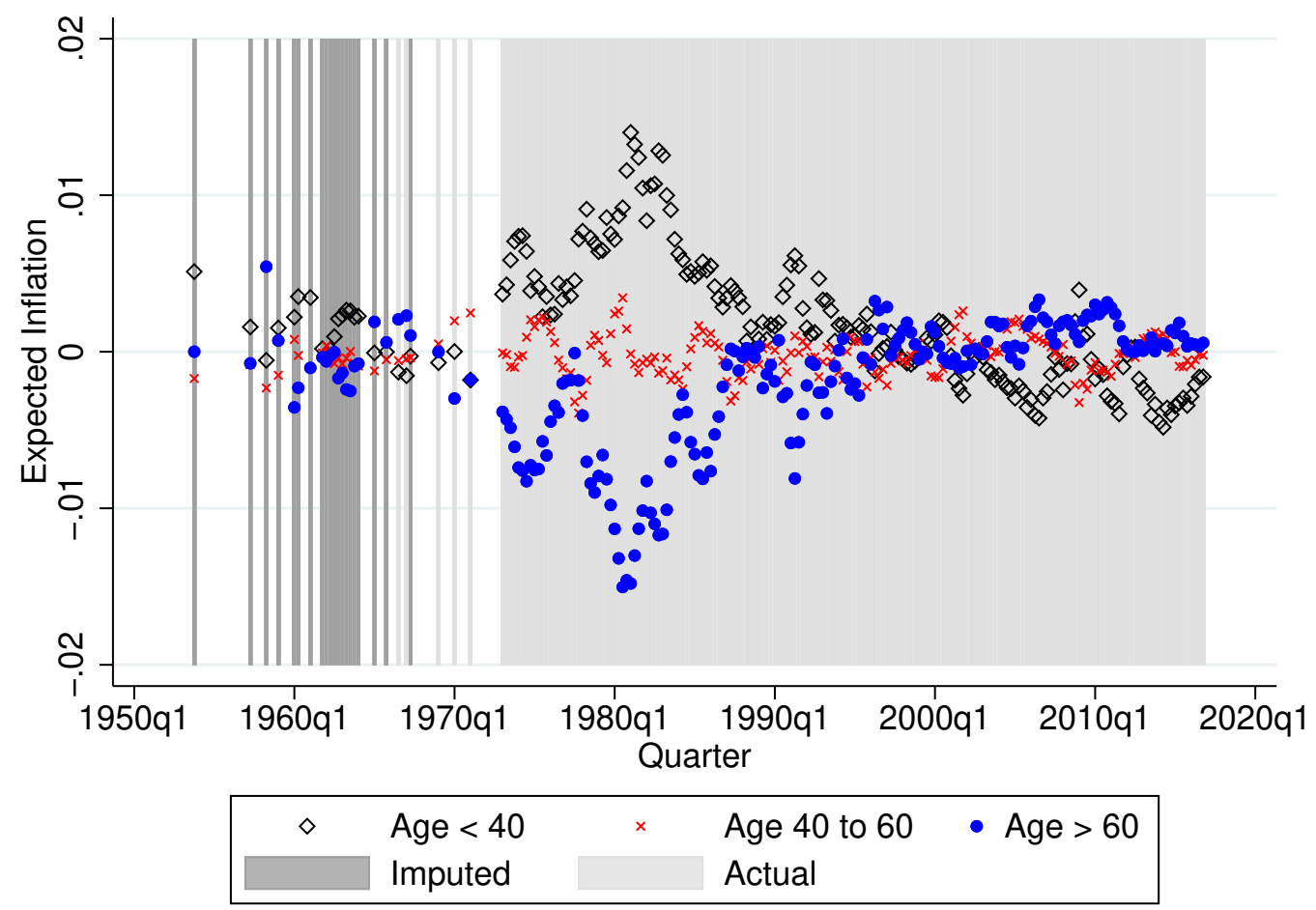

Figure 4: Disagreement about future inflation Four-quarter moving averages of one-year inflation expectations shown as deviations from the cross-sectional mean (MSC)

To illustrate the estimation results, let's first consider the variation in inflation expecta- 
tions in the raw data, separately for different age groups. Figure 4 (updated from Figure I in Malmendier and Nagel (2016)) plots the four-quarter moving averages of mean oneyear (log) inflation expectations of young individuals (below 40), mid-aged individuals (between 40 and 60), and old individuals (above 60), but each of them in terms of their deviation from the cross-sectional mean expectation across all age groups (at that point in time). The periods shaded in light grey indicate survey waves where the $M S C$ elicited expectation beliefs in terms of the actual numerical percent; periods in dark grey indicate survey waves where the $M S C$ elicited only the categorical responses in the periods shaded in dark grey; and they are unavailable in unshaded periods.

The graph shows that there are periods when the younger generations are more pessimistic about future inflation, and other periods when the older generations are more pessimistic. In other words, holding age constant, the relative position of their beliefs changes over time. We can also see that the dispersion across age groups can be large. It reaches almost $3 \mathrm{pp}$ during the high-inflation years of the 1970s and early 1980s. The pessimism of then-young individuals is consistent with learning from experience: Their lives so far had been dominated by persistently high inflation, while older generations have also lived through earlier lower-inflation periods.

Let's now compare those fluctuations with those implied by the model. Malmendier and Nagel (2016) estimate $\theta$ to be 3.044, implying recency-biased weights (cf. Figure 3), and $\beta$ to be 0.672 , implying a strong relationship between the learning-from-experience forecast $\tau_{t+1 \mid t, s}$ and measured inflation expectations $\tilde{\pi}_{t+1 \mid t, s}$. That is, for each $1 \mathrm{pp}$ difference in individuals' learning-from-experience forecast, the model predicts a $0.672 \mathrm{pp}$ difference in one-year inflation expectations on average.

Figure 5 illustrates that the learning-from-experience model is able to explain a large degree of the cross-sectional differences in inflation expectations. The figure (updated from Figure IV in Malmendier and Nagel (2016)) shows both the raw survey data and 


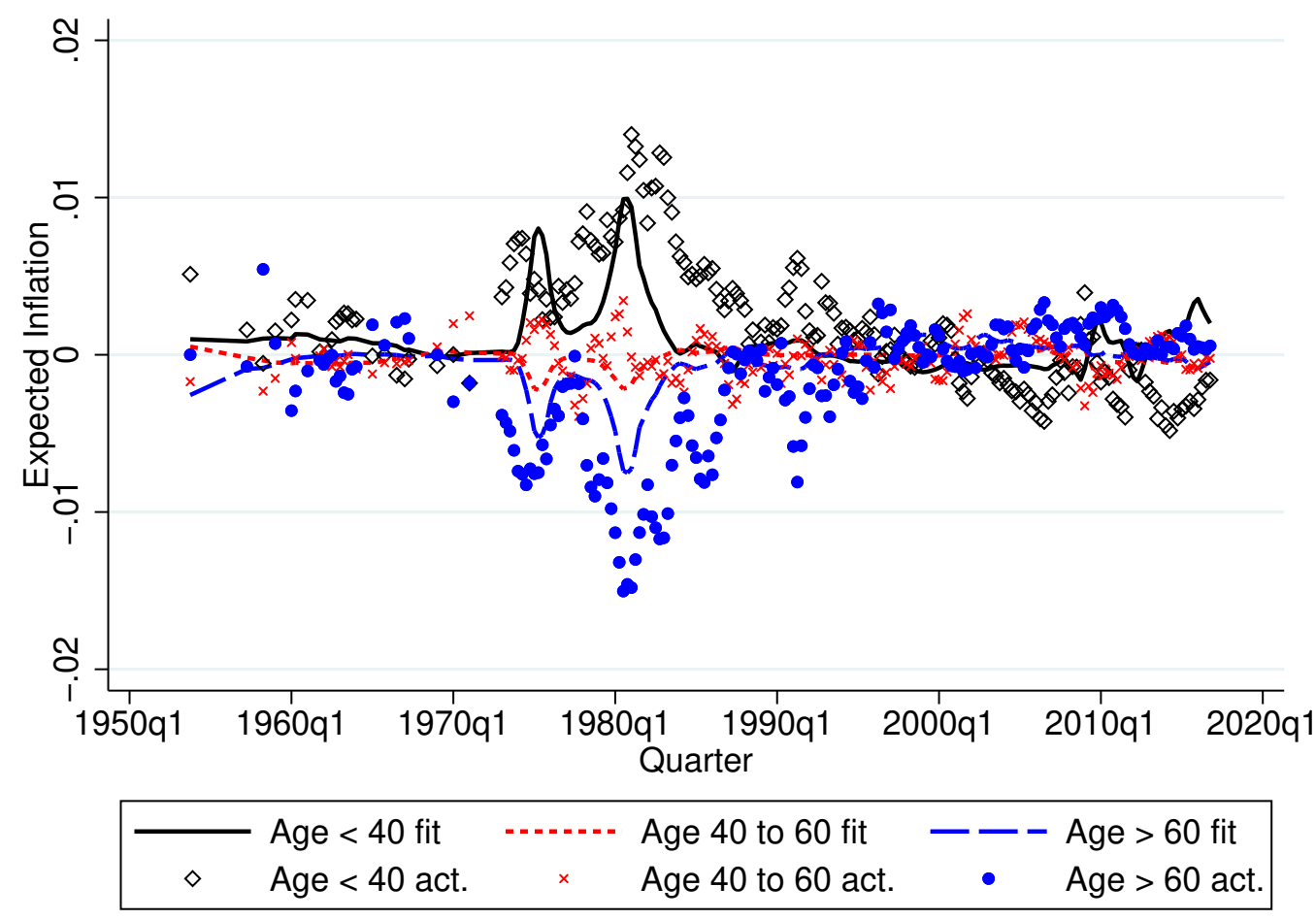

Figure 5: Fitted Experience-based Expectations Fitted and actual relative to full-sample c.s. mean (4-quarter MA)

the fitted values based on the model estimates for the same age groups as in Figure 4 and again expressed as deviations from the cross-sectional mean expectation in each period. We can see that experience effects account to a large extent for the sizable difference in expectations between young and old in the late 1970s and early 1980s, including the double-spike. It also captures all of the low-frequency reversals in the expectations gap between older and younger individuals.

In summary, when we modify existing models of adaptive learning to account for individual heterogeneity in prior lifetime experiences and allow for people to learn more from data realized during their lifetimes, we are able to capture the significant cross-cohort heterogeneity in inflation expectations as well as changes in those differences over time. Differently from prior models, experience-based learning therefore allows for young individuals to update their expectations more strongly than older individuals since recent 
experiences account for a greater share of their accumulated lifetime history.

It is worth pointing out that the implicit weighting of past experiences, based on the estimate of $\theta$ turns out to be very similar to the weighting pattern estimated in the stock-market for the role of past stock-market return experiences on asset allocation. In both Malmendier and Nagel (2011) and the research discussed here the estimates produce roughly linearly declining weights. ${ }^{9}$ This is remarkable since the weights are based on different data sets, and since the outcome variable differs (inflation beliefs rather than stock-market investment choices). Taken together, these findings are suggestive that individuals process different types of macroeconomic experiences in similar ways when they form expectations.

\subsection{Long-term Effects of Inflation Experiences on Economic Decisions}

The effects on personal experiences are detectable not only in individuals' beliefs but also in their actual decision-making. Malmendier and Nagel (2016) provide some evidence on financial decisions, namely, in terms of long-term nominal-rate borrowing and lending.

\subsubsection{Mortgage Borrowing}

Let's start from the borrowing side. The most important financial decisions many households make in their lives is whether to buy a house and whether (and which) mortgage to take out to finance the home purchase. Using the Survey of Consumer Finances $(S C F)$, Malmendier and Nagel (2016) show that past exposure to high inflation realizations predicts higher fixed-rate mortgage (FRM) balances. In this analysis, they regress the log of the cohort-level per-capita nominal position on the learning-from-experience inflation forecast, constructed using the estimate of $\theta=3.044$ (cf. Section 3.2) and controlling for the logs of per-capita income, net worth, as well as time and age fixed effects.

\footnotetext{
${ }^{9}$ The weighting function in Malmendier and Nagel (2011) is controlled by a parameter $\lambda$ which relates to $\theta$ in this paper as $\theta \approx \lambda+1$, and is estimated in the range from 1.1 to 1.9 .
} 
They find that households' fixed-rate mortgage positions are positively related to the learning-from-experience inflation forecast, and that the magnitude of the effect is large: a $1 \mathrm{pp}$ difference in the learning-from-experience forecast corresponds to a 0.35 change in the log of the fixed-rate mortgage balance, which is between a third and a quarter of its standard deviation. That is, consumers who have lived through high-inflation periods seek to invest their money in real estate, presumably as an inflation hedge, and they tend to lean towards fixed-rate financing.

The preference for fixed- over variable-rate borrowing can be derived directly from experience-based overestimation of inflation rates: The present value of an FRM obligation is the sum of the discounted future payments, which are fixed. The present value of an adjustable-rate mortgage (ARM), instead, is the sum of discounted future payments that adjust up and down with future interest rates. A borrower who expects higher inflation and hence higher nominal interest rates will discount any future nominal amount by more, including future FRM payments. In the case of variable rates, instead, such a borrower both expects higher future nominal ARM payments and discounts them using a higher nominal interest rate. Hence, borrowers whose past inflation experiences have lead them to expect higher inflation and interest rates perceive FRMs to be relatively cheaper.

Empirically, Malmendier and Nagel (2016) only obtain a noisy (insignificant) negative estimate of the relation between experience-based inflation forecasts and variable-rate mortgages, which is likely due to the small sample size and lack of detailed information about mortgage contracts in the SCF. Botsch and Malmendier (2020) overcome these difficulties using the the Census Bureau's Residential Finance Surveys (RFS). The RFS data are unique in that they survey both the household and the mortgage servicer, providing both demographic and geographic household information and mortgage contract terms. Using the RFS data they are able to show that individuals with high lifetime 
inflation experiences overestimate future (nominal) interest rates and choose fixed rates over variable rates, even at times when adjustable-rate mortgages (ARMs) are advantageous. Their structural estimates imply that $1 \mathrm{pp}$ of experienced inflation increases a borrower's willingness to pay for an FRM by 6-14 basis points, implying a strong aversion to variable-rate borrowing. Households who would otherwise have chosen an ARM pay $\$ 8,000-\$ 16,000$ in year-2000, after-tax dollars for their experience-driven choice of an FRM over their expected tenure in the house.

Their estimates imply that approximately one in seven households (10-15\% of the population) were close enough to indifference between an FRM and an ARM that we can attribute their FRM choice to long-lasting effects of their past exposure to high inflation. These influences were particularly strong in the wake of the Great Inflation: Given the relative costs of fixed- versus variable-rate mortgages, the generation of Baby Boomers should have taken out one million fewer FRMs in the late 1980s, and still half a million fewer in the late 1990s. The costs of these deviations are large - about $\$ 14 \mathrm{bn}$ in excess payments in the late 1980 s, and still almost $\$ 9$ bn in the late 1990 s.

Overall, the long shadows of the Great Inflation appear to strongly influence mortgage financing choices and the resulting mortgage market structure, and the resulting financial costs to the household are large.

\subsubsection{Homeownership}

There is also evidence that the long-lasting effects of inflation experiences affected not only mortgage choices and the composition of the mortgage market, but also the more fundamental question whether to become a homeowner at all, i. e., the underlying tenure choices and structure of the housing market.

The Malmendier and Nagel (2016) study cited above already indicates that inflation experiences might influence homeownership as their analysis of the $S C F$ data reveals that high inflation experiences predict higher fixed-rate mortgage balances, and hence likely 
homeownership.

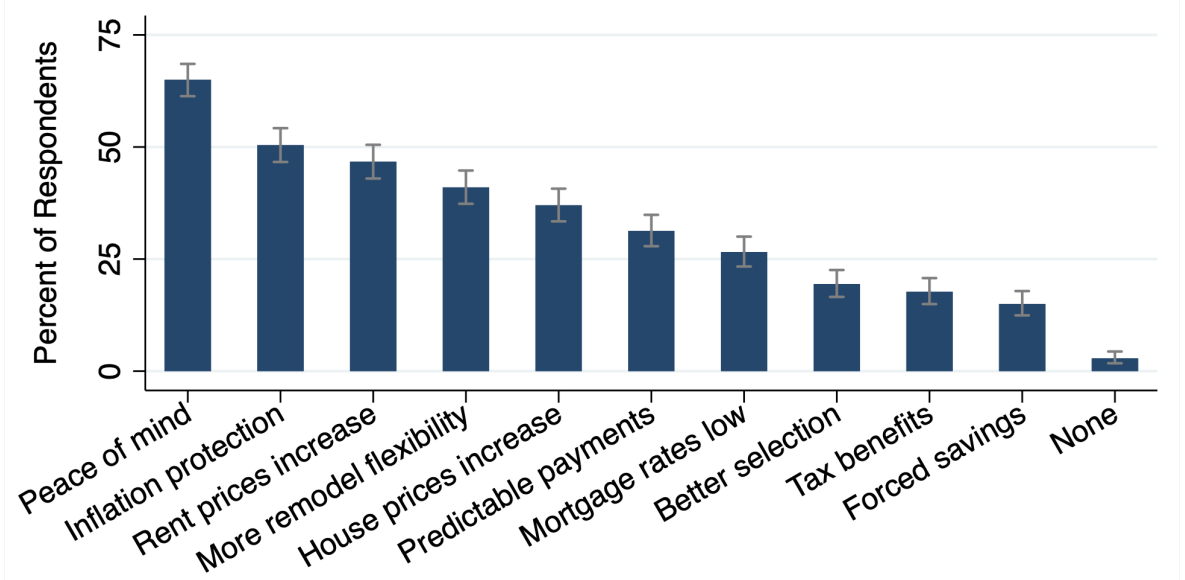

Figure 6: Reasons for Buying a Home. Respondents were asked "What do you think are good reasons for buying a home?" and could select all options that apply. Order of options was randomized. The graph shows the percent of respondents selecting each option and $95 \%$ confidence intervals. Survey responses from 700 homeowners in Germany, Ireland, Italy, Portugal, and Spain.

Malmendier and Steiny (2018) investigate this question directly and test whether households with high inflation experiences turn to real estate as an inflation hedge. ${ }^{10}$ First, they field a survey across several European "low ownership" and "high ownership" countries, including 700 homeowners from Austria, Germany, Ireland, Italy, Portugal, and Spain. Participants were asked what they believe to be good reasons for buying a home and given a choice of 10 options, shown in Figure 6. As the figure reveals, about half of all respondents chose 'Inflation protection' as a reason. If we put "protect against inflation" and "protect against rent price increases" together, concerns about future price increases dominate all other categories ( $72 \%$ of respondents selected at least one of these options). Malmendier and Steiny (2018) also report that a third of all respondents say that concerns about inflation impacted their own homeownership decision, and the latter

\footnotetext{
${ }^{10}$ While the classic Gordon (1962) growth model implies such behavior, empirical tests of whether real estate and real estate investment trusts (REITs) act as inflation hedges have mixed results; cf. Anari and Kolari (2002), Brounen et al. (2014), Case and Wachter (2011), Fama and Schwert (1977), and Liu et al. (1997).
} 
result is concentrated among homeowners who personally experienced high inflation. In other words, the inflation-hedge motive turns out to be more important to homeowners than reasons such as tax benefits to owners, better selection of homes to buy versus rent, low mortgage rates, and even increasing house prices.

Taking this notion to the data, the authors first utilize the American Community Survey (ACS) to study the tenure choices among immigrants to the U.S. This focus provides the unique opportunity to compare the behavior of households with different histories of inflation exposure (in their different home countries) while holding their current housing market (the U.S.) constant. The authors find that personal inflation histories, as determined by time spent in their countries of origin and the U.S., significantly predict homeownership decisions. A one log-point increase in experienced inflation predicts a 4 pp increase in the likelihood of ownership, even in a new and common housing market.

They estimate similar results when comparing inflation experiences and homeownership decisions across and within European countries. Homeownership rates vary significantly within Europe, ranging from less than half of all households owning their home in Germany and Austria, to more than $80 \%$ in Slovakia, Hungary, and Spain. Using data on tenure choices of households from 22 European countries in the European Central Bank's Household Finance and Consumption Survey (HFCS), Malmendier and Steiny (2018) estimate that, across countries, a 1 log-point increase in experienced inflation corresponds to an $18 \mathrm{pp}$ increase in the likelihood of ownership for the average household. Linking back to the fixed- versus variable-rate implications discussed above, they also show that experienced inflation is a stronger predictor of ownership in countries with access to fixed-rate financing. Finally, relying exclusively on the smaller within-country (or within-country-year) variation, they show that a 1 log-point increase in experienced inflation predicts a $3 \mathrm{pp}$ increase in the predicted probability of homeownership for the average household, similar to their $A C S$ estimates. 
Their results indicate a large influence of past inflation experiences on housing markets. The magnitude of the estimated effect is significant also in comparison to the effect sizes of other known determinants. For example, the estimated effect of a one log-point change in experienced inflation is associated with a change in homeownership roughly half as large as a one standard deviation change in measures of rent control, tax benefits to homeowners, and price-to-rent ratio and 1.2 times as large as a one standard deviation increase in buyer transaction costs.

I note that, while the discussion here has focused on inflation experiences, other past experiences could plausibly exert an influence as well under the experience effect hypothesis. For example, using a similarly constructed measure of lifetime experiences of house prices, Malmendier and Steiny (2018) estimate a positive, albeit weaker and less robust relationship with homeownership compared to the effect of experienced inflation. One explanation for the weaker result is the more limited availability of historical house-price data across countries, compared to inflation data. Even within the more limited set of countries, though, inflation experiences dominate house-price experiences.

The key takeaway is that individual exposure to past inflation is a powerful predictor of tenure choice, also relative to past house-price movements. The national memory of high versus low inflation appears to shape housing markets.

\subsubsection{Investment}

On the investment side, the same logic we layed out above to derive a preference for fixed-rate borrowing implies an aversion to fixed-rate investments. Investors who have personally experienced high inflation and thus overestimate future inflation rates value fixed-rate obligations less than other investors and hence are more willing to incur them as borrowers and are less willing to finance them as lenders.

Malmendier and Nagel (2011) provide a first piece of evidence in this direction by relating experienced real bond returns to bond market participation. They calculate real 
bond returns from the annual total return index of 10-year U.S. Treasury bonds provided by Global Financial Data, deflated with Consumer Price Index (CPI) inflation rate from Shiller (2005). That is, while the explanatory variable is not inflation itself, the inflation rate enters negatively. They show that individuals who have lived through periods of low real bond returns (and hence typically high inflation) are more wary of holding longterm bonds, including direct government bonds, corporate bonds, tax-free mutual funds, and non-money market mutual funds with a bond share. A change from the 10th to the 90th percentile of experienced bond returns is associated with an increase of about $11.4 \mathrm{pp}$ in the probability that a household participates in the bond market, which is large compared to average bond market participation of $37.6 \%$ in their sample. As the authors acknowledge, while these results are less robust to variations such as restricting the sample to the modern-SCF sup-period (since 1983) or introducing cohort dummies than the corresponding experience effects in the stock market, the root of this lack of robustness is directly related to the role of past inflation, namely its persistent decline in the 1980s. Since the mid-1980s, young individuals always had higher experienced bond returns than older individuals so that the cross-sectional differences between young and old in experienced bond returns are much more persistent than those in experienced stock returns, removing sources of identification.

Another piece of evidence is provided by Malmendier and Nagel (2016), who related investment in fixed-rate bonds directly to experience-based inflation forecasts and investment in fixed-rate bonds. Their estimations (also on the $S C F$ data) yield a negative albeit insignificant relationship between experience-based inflation forecasts and households' nominal bond positions. It appears that it will be necessary to go beyond the $S C F$ and identify superior data sources with details on individuals portfolio and the fixedrate investment opportunities in order to test for and identify experience effects on the investment side. 
The strongest evidence on the influence of inflation expectations to date probably comes from Armantier et al. (2015). They ran an incentivized survey experiment regarding hypothetical investment choices that allow for payoffs to be indexed to inflation. They find that individuals on average allocate more money in a hypothetical investment vehicle whose payoff is indexed to inflation when they expect higher inflation.

Overall, these findings complement the evidence in Leombroni et al. (2020) that disagreement about future inflation between younger and older households in the late 1970s, as measured in the survey data, helps understand household borrowing and lending, portfolio choices, and prices of real assets.

\subsection{Inflation Experiences of Experts}

Finally, our focus on inflation experiences is a useful setting to illustrate key feature (4), the "robustness to learned information." Research has shown that even highly trained and well-informed professionals are influenced by their personal experiences when forecasting future inflation and taking decisions based on these inflation forecasts. Malmendier et al. (2021) focus on central bankers, namely, members of the Federal Open Market Committee (FOMC) in the U.S., and analyze their inflation forecasts as well as monetary policy decisions. The governors and regional Fed presidents who form the FOMC presumably have all available information related to inflation at their finger tips, and they have staff who compiles it for them and runs models for them. And yet, Malmendier et al. (2021) show that their personal inflation experiences significantly influence their inflation forecasts, the tone of their speeches and statements, and their votes on the FOMC.

They apply the model outlined in Section 3.2 to the individual FOMC members. Starting from inflation forecasts as the outcome variable, they utilize the Monetary Policy Reports, which the FOMC submits to Congress in February and July and which contain 
each members inflation forecasts. ${ }^{11}$ The data for each member's personal inflation experiences (and resulting experience-based forecast) is again based on annualized quarterly changes in the log CPI from Shiller (2005).

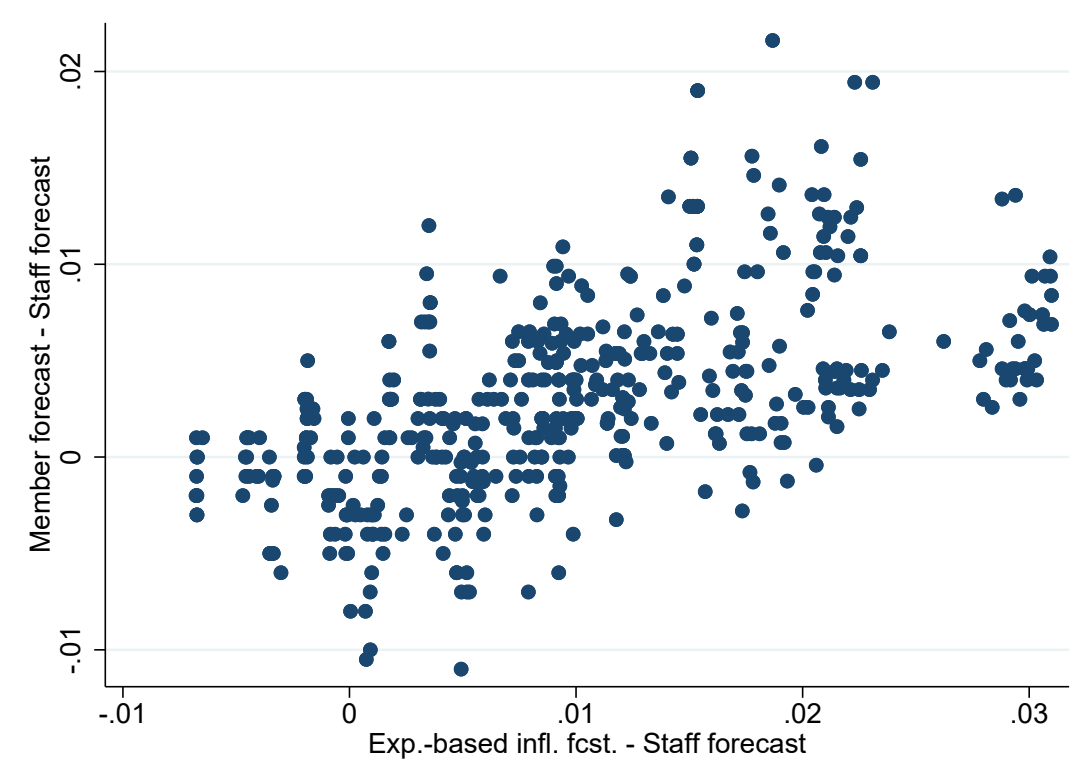

Figure 7: FOMC Members' Inflation Forecasts and Experience-based Forecast. Member forecasts from semi-annual Monetary Policy Report to Congress, 1992 - 2007. Staff forecasts are Greenbook forecast from the same period. Experience-based forecast are AR(1) model forecasts estimated based on weighted life-time inflation data for each FOMC member.

Figure 7, replicated from Figure 1 of Malmendier et al. (2021) with an extended sample period, illustrates the results of the corresponding OLS regression of FOMC members' inflation forecasts in the MPR on their experience-based forecasts. Note that both the dependent and the independent variable are normalized by subtracting the corresponding staff forecast (from the Greenbooks), which helps account for time-specific factors. The scatter plot illustrates the significantly positive relationship between experiences and beliefs, as well as the high $R^{2}$ of $34.7 \%$ of the underlying regression. The results are

\footnotetext{
${ }^{11}$ The individual FOMC members' forecasts become available with a 10-year lag, and the sample in Malmendier et al. (2021) runs from 1992-2004, covering 26 FOMC meetings. For this replication, I extended the data to 2007. The forecasts are for the period from Q4 of the previous year to Q4 of the current year. The July report also contains a forecast for Q4 of the current year to Q4 in the next year. The data set is described in more detail in Romer (2010).
} 
robust to the inclusion of an array of fixed effects, including time and member fixed effects. In other words, the heterogeneity in FOMC members' lifetime experiences of inflation results in significant heterogeneity in their beliefs about future inflation.

An interesting observation is that, as Romer and Romer (2008) have shown, the deviation of FOMC members' forecasts from the staff forecast in the Greenbooks tends to reduce the forecast accuracy. The results here suggest that experience effects help explain those deviations. In other words, personal past experiences induce FOMC members to make worse forecasts than they would if they were simply following the suggestions of their staff.

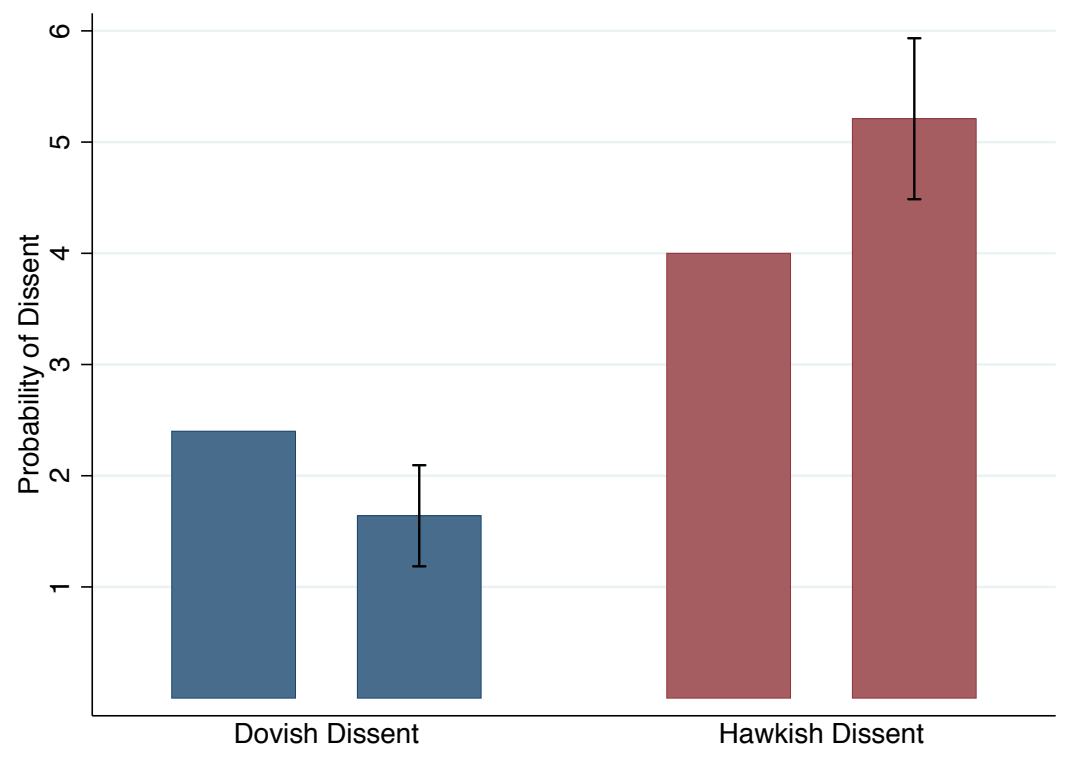

Figure 8: Inflation experiences and FOMC voting behavior. The blue and red left bars indicate the baseline probabilities of dissent. The right bars show the effect of a $+0.1 \mathrm{pp}$ rise in experience-based inflation forecast on the respective dissent probabilities.

These experience effects influence not only stated beliefs but also monetary policy decisions. Malmendier et al. (2021) compile FOMC meetings from March 1951 to January 2014 and show that FOMC members' voting decisions were significantly influenced by the inflation experiences they had accumulated during their lifetimes so far. To map the experience-based forecasts into a voting decision, they first link the individual experience- 
based inflation forecasts to the desired level of nominal interest rates using a subjective version of the Taylor (1993) rule, in which FOMC members evaluate deviations from the inflation target in terms of their own experience-based inflation forecasts. The resulting estimates are both statistically and economically highly significant. A one within-meeting standard-deviation increase in the experience-based inflation forecast raises the probability of a hawkish dissent by about one third, and it lowers the probability of a dovish dissent also by about one third, relative to the unconditional dissent probabilities (cf. Figure 8).

The significant relationship between personal past experiences and votes means that we can detect experience effects in the actual decisions of professional, highly informed decision-makers. The low baseline probabilities of dissent (2-4\%) in the respective left bars in Figure 8 also indicate that dissenting votes are a low-frequency outcome. FOMC members, and in particular governors, tend to avoid formally casting a dissenting vote, even when they vocalize concerns at the meeting. Their statements and speeches, on the other hand, can be used to tease out the more subtle differences in desired interest rate changes. Malmendier et al. (2021) construct a data set of all "Speeches and Statements" from the Federal Reserve Archival System for Economic Research (FRASER) as well as hand-collected speeches from the websites of the regional Federal Reserve Banks (FRBs), and then show that FOMC members use a significantly more hawkish tone when their lifetime experiences imply a higher experience-based inflation forecast.

Not surprisingly, the experience of the Great Inflation in the 1970s has a large influence on these estimates. Much of the identification comes from whether and at what age an FOMC member experienced the Great Inflation. However, there is one peculiar individual case in the Malmendier et al. (2021) study gives us a clue of other periods of influence being at work as well, even if not captured: the case of Henry Wallich and the German Hyperinflation. The 1975-1986 Fed governor was born in Berlin in 1914, into a family of 
bankers, lived through the 1923 hyperinflation growing up, and after studying in Munich and Oxford, escaped the Nazi regime in 1933 to Argentina and then the US. He obtained a Ph.D. at Harvard, was a profesor at Yale, and had a long career at the Fed (Engelbourg, 2001). During that time he became (in-)famous for his relentless fight against inflation and unwillingness to allow for other considerations (unemployment). To this day, he still holds the Federal Reserve record of dissents with the chairperson's proposal (27). In fact, Malmendier et al. (2021) have to accommodate Wallich with a separate hyperinflationexperience dummy in their estimation. As former Fed Governor Nancy Teeters put it, describing the Fed's efforts during the Volcker disinflation policies, "Henry Wallich was our real problem. ... For some people, like Henry, who lived through the hyperinflation in Germany, fighting inflation was the only thing. In this country, we really didn't have anything like it. During the 1930s, prices went down." ${ }^{12}$ In other words, growing up in different countries left a lasting influence on beliefs and choices, even among highly informed experts.

\subsection{Sources of Identification}

The Wallich-Teeters example not only helps illustrate the power of experience effects 'even among experts,' but also points us to sources of identification other than differences in birth year and resulting lifetime experience. While Nancy Teeters was 16 years younger than Henry Wallich, their different attitudes were determined by where they grew up (U.S. vs. Germany). Experiences are determined by what I live through and observe around me, which in turn depends on location. The same source of identification was present in the "Buy or Rent" study of Malmendier and Steiny (2018) to the extent that cross-country differences in inflation experiences help explain differences in housing markets. Even more "local," we saw in D'Acunto et al. (2021) that household-level differ-

\footnotetext{
${ }^{12}$ Federal Reserve Board Oral History Project, Interview with Nancy H. Teeters, 2008
} 
ences in personal consumption bundles and the price changes therein induce differences in inflation expectations.

Location-based influences on the direction and extent of experience effects have also been shown in other arenas, for example, the stock market. Ampudia and Ehrmann (2017) show that the finding from Malmendier and Nagel (2011) that stock-market experiences in determining stock market participation also holds across countries in the euro area: higher experienced stock-market returns make households more willing to take financial risk and increase their stock-market participation.

Another example are unemployment experiences. Malmendier and Shen (2020) argue that past unemployment experiences scar consumers and lead to long-lasting reductions in consumption spending. Using data from Panel Study of Income Dynamics (PSID), they find that unemployment experiences induce persistent pessimism about the future financial situation and lower consumption expenditures, after controlling for the standard life-cycle consumption factors. This is in spite of the finding that - after controlling for the usual predictors of future income such as current income, wealth, and employment status - actual future income is uncorrelated with those experiences further in the past. Also, due to their experience-induced frugality, scarred consumers build up more wealth.

Their paper is the first to consider macro-level experiences (national unemployment rate), more local experiences (statewide unemployement rate), and individual-level experiences (personal unemployment) jointly and to show that all of them exert a significant influence, with personal unemployment being the strongest determinant.

This latter example of "consumption scarring" also points to even further sources of identification, beyond birth year and location. Any individual-level variation in exposure to realizations of the variable of interest can be of interest. As a last example, consider Das et al. (2020), who show that individuals' socioeconomic status (SES) influence their macroeconomic expectations. They find that people earning a higher income or and those 
with a better education tend to be more optimistic about future macroeconomic developments, including business conditions, the national unemployment rate, and stock market returns. As a result, SES-driven expectations could help explain why higher-SES individuals are more inclined to invest in the stock market and more likely to consider purchasing homes, durable goods, or cars. While these effects might work through multiple channels, they are consistent with individual-level "coloring" of attitudes and expectations in response to individual level signals. In fact, the authors also find that the spread in beliefs between high- and low-SES individuals diminishes significantly during recessions, when there is presumably less divergence in individual level signals.

I will return to other dimensions of interpersonal differences in experience, including race and gender, and their implications for the dynamics of inequalities in Section 5.

\section{Key Features of Experience Effects and Next Steps}

The literature surveyed in the previous has illustrated that experience effects are powerful and at work in many economic settings. It also allowed us to discern several key features. We saw that,

1. Experiences over one's lifetime so far have long-lasting effects on beliefs and choices for years and decades to come.

2. Recent experiences tend to have the strongest impact (recency bias), but even outcomes experienced many years ago continue to have a measurable impact if large enough.

These long lasting effects can help to understand intergenerational differences ("Gen X versus Gen Y") due to different past experiences, but also why the same experience can influence different cohorts differently, depending on the lengths of and realizations during their prior lifetimes so far. We also saw and discussed the finding that 


\section{Experiences affect even experts.}

The third feature of experience effects, though, namely that

\section{Experiences are domain-specific.}

was featured only in the discussion of the neuroscientific underpinnings of experience effects, and not in the discussion of the existing evidence in economics. This third feature describes the observation that experience-based beliefs in one setting (say, the stock market) do not necessarily translate into other settings (say, other, correlated asset markets), even if the realizations of the underlying stochastic processes are correlated. As we discussed, the type of stimuli related to the first setting might be different in nature than those in the other setting, triggering different emissions of neurotransmitters along different synapses. That means that, while experience effects are predicted to be at work and have shown to be at work in many different economic domains (stocks, bonds, inflation, interest rate expectations, unemployment experiences etc.), we do not predict cross-fertilization between different realms of economic decisions.

Malmendier and Nagel (2011) provide some evidence in that they show that stockmarket experiences affect stock-market investment, bond-market experiences affect bond investment, but their is no significant cross-over experience based learning. That is, even though experienced bond returns are about as volatile in real terms as experienced stock returns during their sample period, the experience-based learning and risk attitudes are specific to the domain of experience.

While not directly tested yet in other applications outside of finance, the concept is the underpinning of the respective empirical tests in that they relate the outcome variable of interest (say, inflation expectations) to corresponding realm of experiences (inflation experiences). The COVID-19 crisis will provide for interesting opportunities to test directly for domain specificity as, in some countries (like the US), unemployment 
rates were affected, but not stock-market returns, while other countries (like Spain) saw negative ramifications in both domains.

Panel A: Good Realizations Early in Life

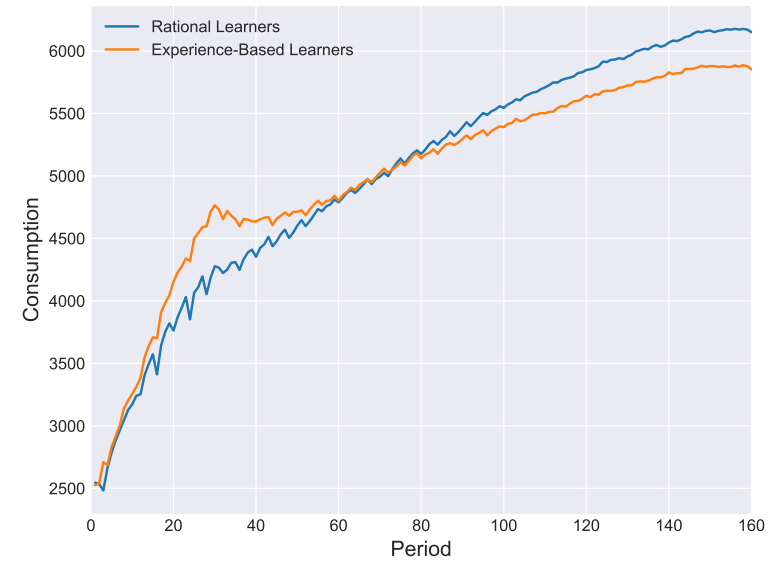

Panel B: Bad Realizations Early in Life

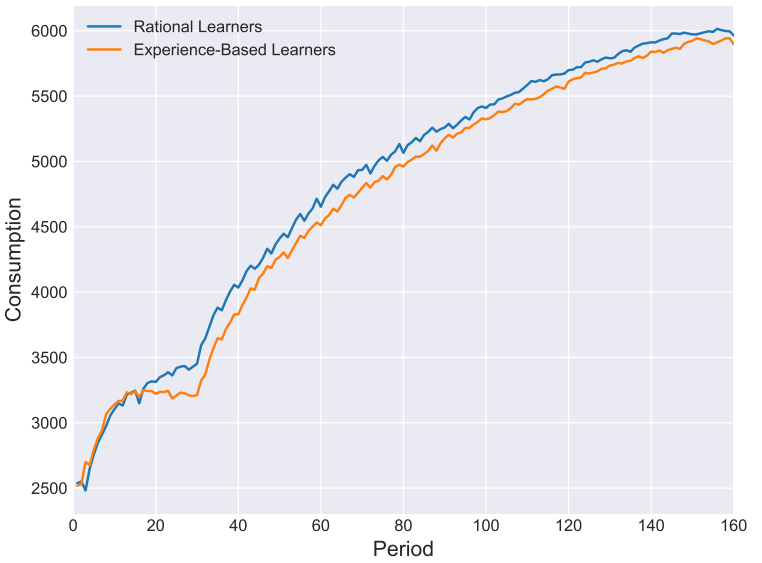

Based on simulated data from the model of Malmendier and Shen (2020). Average consumption for rational learners and experience-based learners (with $\lambda=1$ ) in the low-education group, based on 10,000 lifetime simulations for each type and then restricted to those simulations where agents have, or in the rational case would have, a believed delta of 0.025 or less at period 30 in Panel A and a believed delta of 0.1 or greater at period 3 in Panel B.

Figure 9: Average Life-Cycle Consumption

Positive versus negative experiences. Another aspect that is still missing in the existing body of work on experience effects is conclusive evidence on "direction of exposure" playing a role. While many of the examples discussed here come from crisis periods, such as the Great Depression, the Great Inflation, or even the German hyperinflation, the underlying research has not found asymmetries in the data. Negative experiences with a certain asset or in a certain market induce individuals to shy away from taking the respective risk, and positive experiences encourage individuals to take more of that risk, whether we look at the stock-market (Malmendier and Nagel, 2011; Ampudia and Ehrmann, 2017), at inflation Malmendier and Nagel (2016); Malmendier and Steiny (2018); Botsch and Malmendier (2018), or at unemployment Malmendier and Shen (2020). On the other hand, theories such as prospect theory emphasize the more prominent role of "losses" compared to "gains" in human psychology, and much of the neuropsychology evidence cited above focuses on the negative side of experiences, such 
as the role of stress and trauma.

Figure 9, which is replicated from the Appendix of Malmendier and Shen (2020), illustrates the assumption of two-sided (symmetric) effects has interesting implications, here in the context of past unemployment experiences and illustrated via simulations of a Low et al. (2010)-style lifecycle consumption model. Panel A considers consumers who were "lucky" early in life (no income/job loss). In that scenario, experience-based learners (in orange) believe their risk of job loss to be small (0.025 or less) in period 30 of their lives, even though the true probability of them losing their job is 0.049 in the simulations. As a result, they engage in pronounced overconsumption in the early periods, relative to the rational benchmark (in blue), for which they have to pay later in life. Panel B illustrates the opposite scenario. Here, the simulation considers only consumers who had bad luck early in life and, at period 30, believe their risk of job loss to be 0.1 or greater, instead of the true probability of 0.049. In this "unlucky" group, experience-based learners consistently consume less than their rational counterparts for almost their entire lives and build up significant wealth reserves due to excess frugality. Malmendier and Shen (2020) show that these behavioral patterns hold empirically.

Further studies with longer, more detailed panel data sets will need to confirm or reject the (almost) symmetric nature of experience effects in this and other applications.

Big versus small experiences. Our emphasis on crisis periods throughout this article (and in prior research) also might seem to imply that only significant events can generate experience effects. Here, too, the neurological foundations help to rectify this view. As we discussed in Section 2, any prolonged or repeated exposure to stimuli is able to rewire the brain. For example, in the context of the long-term effects of adverse experiences, neuropsychiatrists often emphasize that there is not only "Big-T" trauma, such as heart attacks, car accidents, war experience, or adverse childhood experiences, but also "small-t" trauma, the daily slides and paper cuts, repeated microaggressions, 
financial worries, or food insecurity that trigger persistent stress. Small-t trauma is harder to discover because it is never ending, and often harder to treat. ${ }^{13}$ Yet, it does shape you in a similar way.

Our discussion of the lasting effects of "daily price signals" in Section 3.1 already indicates as much. It revealed that not only major macro shocks, such as the 1970s Great Inflation, but also our daily environment, which determines what price signals we see every day, can have significant long-term effects on beliefs and choices. In our discussion of gender- and race-based determinants of experience-based learning in Section 5, we will return to this point.

Theoretical framework. Finally, we also need progress on the theoretical side to fully capture the empirical features that have already been established, tease out their implications for choice behavior, and derive predictions of additional behavioral patterns. We have established the need to go beyond the standard, information-based approach in economics and to capture the "re-wiring" that occurs in our brains as we are accumulating experiences throughout our lives.

The existing theoretical literature provides several promising building blocks but not yet the full framework. Related work includes models of over-inference such as models of natural expectation formation (Fuster et al., 2011, 2010) and of over-extrapolation more recent observations (Barberis et al., 2015, 2016). These approaches recognize the significant recency bias in investors' belief formation, and predict a strong reaction to a recent crisis and excessive pessimism in the subsequent months, but do not capture the long-lasting crisis effects on consumer beliefs and economic choices.

Other approaches are able to capture longer-lasting effects by assuming that scarring events (like financial crises) change how people think about tail risk (Kozlowski et al., 2020). Here, though, we would not obtain domain specificity if risky variables are cor-

\footnotetext{
${ }^{13}$ See, for example, Barbash (2017).
} 
related, nor an effect even for those who "know better" than updating their model in response to the recent crisis. The most fundamental difference is that the model still relies on "information" as the sole care determinant. There is no role for "personally experienced" outcomes to be stronger than learned information.

Other variants, which capture most but not all aspects of experience-based learning include Nagel and Xu (2019), who model asset prices when agents have gradually fading memory. Here, the decaying memory of observations in the past is the only modification to an otherwise standard Bayesian parameter learning model.

Finally, several papers directly assume that experiences enter beliefs through special weighting, including the simple OLG framework from Malmendier et al. (2020a,b) and the analyses of macroeconomic shocks and portfolio holdings in Ehling et al. (2018) and Collin-Dufresne et al. (2017). These frameworks can capture all stylized features (or could, with slight modifications), and also allow to derive additional implications, e.g., on the dynamics of stock-market investment or the implications of demographic changes in Malmendier et al. (2020a). However, they are also specifically designed to describe financial markets and do not lend themselves easily to studying broader choice behavior.

A related strand of literature that is pursuing a more fundamental move towards a framework that would allow for time- and context-varying choice behavior is the literature on memory and retrieval (Wachter and Kahana, 2019; Bordalo et al., 2020). These approaches model directly memory-based anchoring and argue, very much in line with the experience-effects literature and its neuroscience foundations, that the basic mechanisms of memory imply that the information embedded in past experiences is disproportionately accessible to decision makers. As such, their approach naturally captures the stylized features (1) and (4), and could easily incorporate (2), the recency bias, with some adjustment. Moreover, much of their model revolves around the role of "context," which is closely related to domain-specificity. As they argue, contextual stimuli act as 
cues that trigger recall of similar past experiences.

\section{Broader Applications and Implications for Future Research}

The discussion of the neuroscience foundations of experience effects in Section 2 as well as the stylized features in Section 4 present experience-based learning as a fundamental feature of human belief formation. The processing of stimuli, the anchoring of information in memory, the retrieval, and ultimately the influence on decision-making, all apply very broadly and beyond those areas we discussed in Section 3. And, if differences in individuals exposure to past "realizations" affect their beliefs in the long-run, experiencebased learning also gives rise to systematic differences by age (birth cohort), geographic location, and socio-economic background as discussed in Section 3.5.

Further determinants of "systematic differences in experiences" easily comes to mind: differences by gender, difference by ethnic and racial background, differences by religion, and so forth. All of these demographic characteristics directly lend themselves to studying experience effects and, vice versa, experience effects hold the promise to change existing approaches towards understanding the root of persistent gender, racial etc. differences. That is, while much of the existing research is focused on the role of inequalities in opportunities, financial constraints, and discrimination, the evidence on experience effects implies that we also need to account for systematic differences in past exposure. Even if all the hurdles and frictions are removed, inequalities might persist if prior exposure "primes" individuals to make systematically different choices. All that is needed to investigate such questions is fine enough data on personal past experiences in an arena of interest and data on individual choices in that same arena.

Gender. Let's start from considering gender differences. If we want to study, say, the determinants of women choosing a career in STEM fields, we will want to obtain data on women's prior exposure to STEM and signals about women being successful in 
STEM and test for the strength of that relationship. Existing literature on "role models" is consistent with this view. For example, Carrell et al. (2010)'s work on "Sex and Science" finds that the exogenous assignment to female professors significantly increases the performance of female students in math and science classes, the likelihood of highperforming female students enrolling in further math and science courses and graduating with a STEM degree. ${ }^{14}$ While this literature on gender-based teacher-student matching does not cover all relevant experiences in a student's prior lifetime, it is suggestive of the role of experience effects: It does not suffice to remove formal hurdles to women entering STEM fields (such as providing equal access to STEM education or STEM jobs). As important as those steps are, gender differences will persist if women do not receive "signals" (stimuli) that anchor the idea of "women in STEM" in their brains. Personal experiences from exposure to these fields in practica and internships, or witnessing and working with other women in STEM (such as STEM teachers) are plausible examples.

While the above argument is theoretical and still needs to be tested in richer data sets, including data on beliefs, we have some empirical evidence from the outcome variable that has been featured throughout this article: inflation expectations.

Gender differences in inflation expectations have been puzzling policy makers at the Fed and internationally for decades. As Jonung (1981) documents for Sweden, for example, women tend to be systematically more pessimistic about current inflation and expect future prices to increase more than men do.

Where do these differences come from? Traditional economic approaches would turn to gender differences in financial literacy or, more generally, education. What D'Acunto et al. (2021) show, however, is not only that those traditional angles fail to explain the

\footnotetext{
${ }^{14}$ Other studies estimating positive and sizable impacts of female teachers on female students include Dee (2007); Muralidharan and Sheth (2016); Lim and Meer (2017), including on long-term outcomes (Lavy and Sand, 2018; Lim and Meer, 2021), with primary-school and middle-school matching affecting high-school outcomes and beyond.
} 
pattern, but also that it is precisely the differences in "exposure" to everyday price signals that can fully explain the gender differences.

Their study uses the same data as D'Acunto et al. (2021), discussed in Section 3.1, which combines survey data on individual perceptions of current inflation and expectations of future inflation with data on actual purchases of non-durable consumption items from the Kilts-Nielsen Consumer Panel $(K N C P)$. Using this data, they first re-establish the gender expectations gap. Differently from all prior literature, they are able to show that even within the same household women tend to have significantly higher inflation expectations than men. Hence, household-level characteristics such as family structures, family income, wealth, savings, and other financial choices cannot drive the gender expectations gap.

The key finding of their study is that this gender expectations gap is fully accounted for by differences in the exposure to grocery prices. That is, when they regress inflation expectations on gender, they estimate a significant gender difference; but when they include a control for being the "main grocery shopper" for the household in the same regression, the gender dummy becomes insignificant, while the indicator for being the main grocery-shopper is highly significant. Moreover both the coefficient sizes and their statistical significance are entirely unaffected by the inclusion of household fixed effects.

We should pause here for a moment to better understand what grocery prices have to do with higher inflation expectations. Figure 10 illustrates that food inflation is significantly more volatile than core inflation, which is the measure used by monetary policy makers that excludes price changes from the food and energy sector. Highly volatile prices, in turn, induce higher inflation expectations - among men and women alike - since consumers appear to remember the price hikes and underweight the subsequent decreases, as shown in a large literature in social psychology, marketing, and economics (Bruine de Bruin et al., 2010; Vlasenko and Cunningham, 2015; Brachinger, 2008; Ranyard et al., 


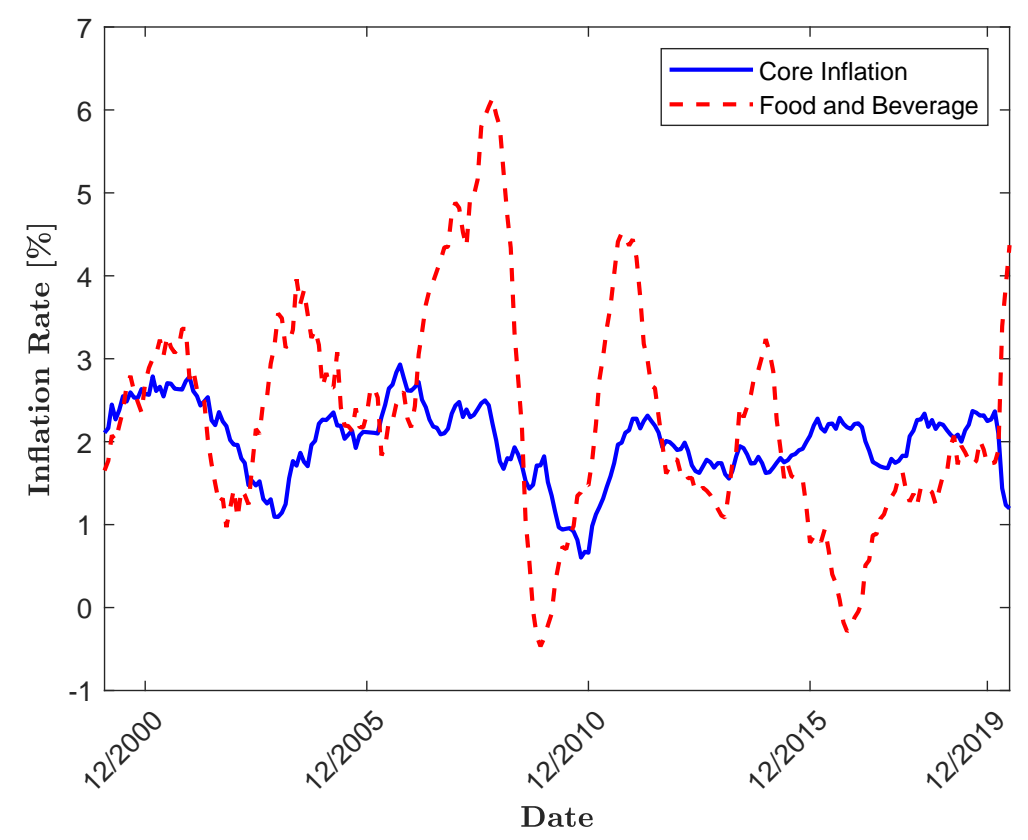

Figure 10: Core versus Food Inflation.

2008; Fluch et al., 2005; Bates and Gabor, 1986; D'Acunto et al., 2021). Hence, it is plausible that higher exposure to volatile grocery prices induce higher inflation expectations. In line with traditional gender roles, that exposure affects women overproporationally.

Another piece of the analysis in D'Acunto et al. (2021) is relevant here: An alternative view might link systematic gender differences to innate differences in the processing of price information or the ability to calculate inflation rates. D'Acunto et al. (2021) show that this is not the case. Relating individual-level inflation expectations to the corresponding inflation perceptions, there is no systematic difference between men and women, neither in the full sample nor in the sub-samples of grocery-shoppers and nongrocery-shoppers; cf. Figure 11.

In summary, we see how differences in the daily environment women and men are placed in can generate differences in beliefs, which in turn are likely to affect choices from consumption and purchases to education, career, and family. In fact, the gender expectation gap exists not only in the context but for a wide array of financial and economic 


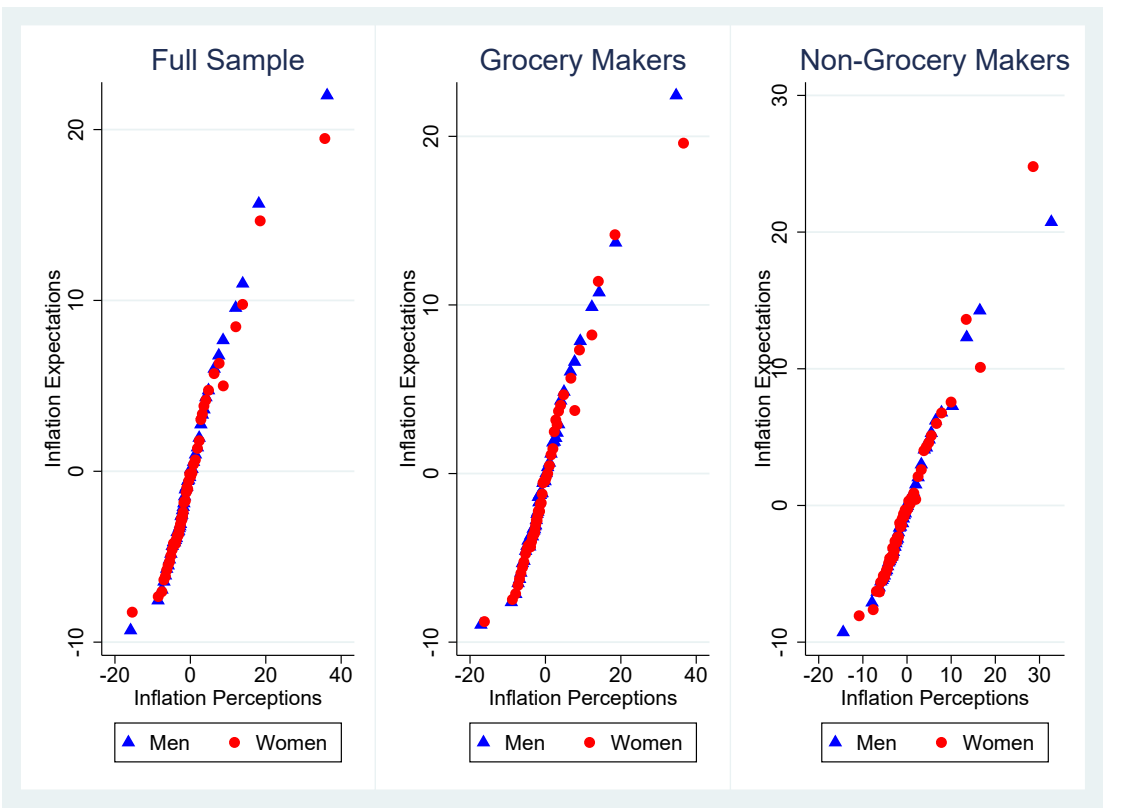

Figure 11: Mapping from Perceptions to Expectations.

variables, from house and stock prices to perceptions of one's own financial situation and the state of the economy, as illustrated in Figure 12 (from the same survey data). The implication of this hypothesis, then, is that it is essential to not just "provide opportunities" and "remove hurdles" but to actively expose women to similar environments as men (and vice versa) if we want to remedy persistent gender imbalances.

Race. The same argument applies to racial inequities. In his much-discussed critique of affirmative action "Reflections Of An Affirmative Action Baby," Yale law professor Stephen Carter points to the downsides of being framed (and stereotyped) as "the best black" - both in limiting the aspirations and perceptions of the "beneficiaries" and in giving the misguided sense that everything has been done to address persistent racism, when instead racist stereotypes are being reinforced. While the arguments put forward in Carter (1991) are well-taken, and largely apply to gender discrimination and genderbased affirmative action (being "the best woman"), the conclusion we would draw from an "experience effects" perspective are different. Carter oppose affirmative action as practiced today and argues that, instead of assigning appointments and slots to minorities, 


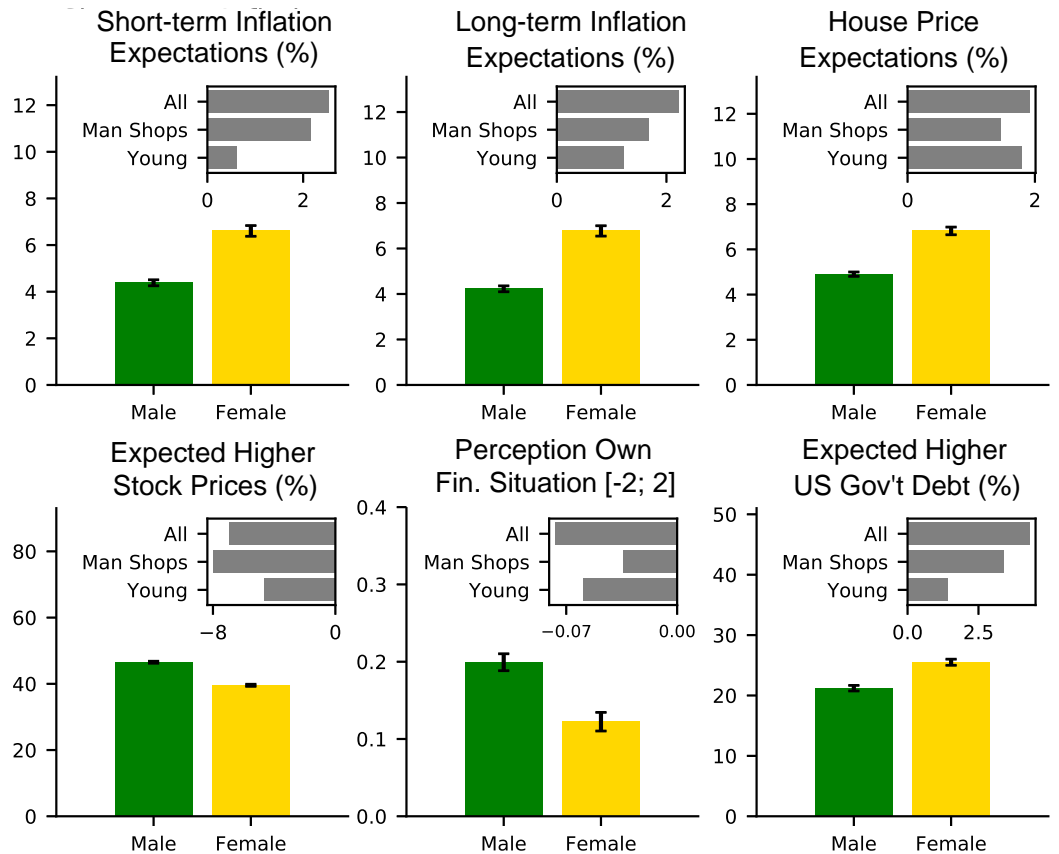

Figure 12: Gender Differences in Beliefs.

it would be preferable to focus on providing and improving the "educational opportunities" for those who might not otherwise have them. The evidence on the long-lasting effects of past experiences imply that we would need to go one step further. Opportunities might not be enough, but we need actual exposure - exposure to better education and to the professional setting where we want to remedy racial imbalances. Generating such exposure - enrollment in the right schools, internships and practica in the targeted professional settings - likely involves a more active role than generating the opportunity, from going into households and explaining the opportunity to help with applications and featuring the achievements of members of the own racial group, and possibly more.

Examples from existing research on role models in the educational context are consistent with the view that "more than opportunities" is needed. Similar to our discussion of teacher-student matching in the context gender differences, racial matching also appears to exert a powerful influence. For example, Gershenson et al. (2021) find that Black students exposed to at least one Black teacher in K-3 are significantly more likely to 
attend high school and enroll in college than their same-school, same-race peers. Turning to college students, Lusher et al. (2018) study the effect of same-race graduate teaching assistants on student outcomes. They estimate a significantly positive effect on grades and attendance. Relatedly, Kofoed and McGovney (2019) show that same-race mentors at the United States Military Academy Westpoint significantly influence occupational choices. While in these and other papers, multiple channels might be at work, they point to the importance of having a personal experience with "a person like you" in the context of interest and being able "to see yourself" in that role, above and beyond having taken advantage of the educational opportunity (being enrolled in a certain college or a specific class).

The evidence goes beyond the student-teacher relationship and also extends to interactions with peers. For example, college freshmen randomly assigned to a peer group with more Black peers who excelled academically in high school were more likely to choose a black roommate the following year (Carrell et al., 2019). Being randomly assigned a black roommate in college has also been shown to predict having more black friends two to three years after the experience (Camargo and Stinebrickner, 2010).

Social attitudes and civic engagement. The same strand of literature points to even broader implications. For example, Rao (2019) exploits a natural experiment in Indian schools to show that interacting with poor students made "upper class' students more prosocial, generous, and less likely to discriminate against a student based on their economic background. in other settings, students who were randomly exposed to a more racially diverse high school have been shown to become more likely to participate in voting later in their lives (Polipciuc et al., 2021) and less likely to register as Republican later (Billings et al., 2021).

Other types of experiences that have been singled out as exerting long-run influence on civic engagement include volunteering or engagement in community-based projects and 
the experience of active, personal mentoring on political and social issues (Perrin and Gillis (2019), Einfeld and Collins (2008), and Sax et al. (1999)).

Health care. As a last area for future research, I would like to single out the provision of and demand for health care services.

On the side of health care providers, Weber et al. (1993) have shown that physicians are very good at drawing on past diagnostic experiences in order to assess a patient and diagnose them accurately. This is especially true for physicians who have more experience, thus larger datasets to draw information from. (See also Hertwig et al. (2004).)

However, the reliance on past experiences can be problematic if doctors lack experience with certain types of ailments or certain types of people. As a result, physicians' personal experience with patients is likely skewed by any demographic characteristics, and this reliance on experience might lead to biases that cause misdiagnoses and possibly mistrust between doctors and patients.

An extreme version of those concerns about experience-based mistrust are the historic betrayals of various ethnic and racial groups, such as experiments to eliminate trachoma and forced sterilizations in native Americans (Canales et al. (2011), Benson (1999); Lawrence (2000)) Similarly, the Tuskegee experiment has been linked to Black Americans mistrusting doctors to save their lives if they are an organ donor (Siminoff et al. (2006)).

All of these examples motivate the need for further research into the role of personal experiences in the health sector.

\section{Conclusion}

The evidence on experience effects laid out in this article suggests that our past experiences exert a more powerful influence on our current behavior than traditional economic models allow for. Daily exposure and its lifetime aggregation have a significant long-term 
impact in all areas of economic decision making. These include macro shocks and "bigT" trauma as well as simple signals we receive in our daily environments and "small-t" traumatic experiences. In either case, the personal exposure to specific outcomes appears to re-wire our thinking in a lasting manner, especially if frequent and repeated.

These mechanisms appear to be at work in any human (in fact, mammal) brain and to affect even well-informed experts such as central bankers, finance experts, or highly trained physicians in their professional decision-making. In other words, experience-based choice behavior is not a question of intelligence, it is the outcome of a biological processes, in particular in our brains.

Many of these differences in past experiences are predictable. They depend on birth year, location, gender, race, and other measurable demographic characteristics. Moreover, with the increasing availability of longer-term individual level data, including administrative data, even experiences that are not predicted by such demographics can be captured and utilized in future research to predict beliefs and choices in the long-run. Moreover, further research will have implications for the dynamics of inequality. Experience effects interact with inequality. As shocks such as the COVID-19 crisis affect different groups of the population differently, the resulting increase in inequality is likely to spill into future years. On the flip side, it also provides for policy implications that would be able to counterbalance (or leverage) such effects. Regulatory entities would benefit from taking the role of exposure, the power of role models, and the long-lasting effects of personal experiences into account.

\section{References}

Ampudia, M. and M. Ehrmann (2017). Macroeconomic experiences and risk taking of euro area households. European Economic Review 91, 146-156.

Anari, A. and J. Kolari (2002). House prices and inflation. Real Estate Economics 30(1), $67-84$. 
Angeletos, G.-M. and C. Lian (2016). Incomplete information in macroeconomics: Accommodating frictions in coordination. In Handbook of macroeconomics, Volume 2, pp. 1065-1240. Elsevier.

Armantier, O., W. Bruine de Bruin, G. Topa, W. Van Der Klaauw, and B. Zafar (2015). Inflation expectations and behavior: Do survey respondents act on their beliefs? International Economic Review 56(2), 505-536.

Barbash, E. (2017, March). Different Types of Trauma: Small 't' versus Large 'T'. Psychology Today.

Barberis, N., R. Greenwood, L. Jin, and A. Shleifer (2015). X-CAPM: An extrapolative capital asset pricing model. Journal of financial economics 115(1), 1-24.

Barberis, N., R. Greenwood, L. Jin, and A. Shleifer (2016). Extrapolation and bubbles. Working Paper, National Bureau of Economic Research.

Bates, J. M. and A. Gabor (1986). Price perception in creeping inflation: Report on an enquiry. Journal of Economic Psychology 7(3), 291-314.

Bear, M., B. Connors, and M. Paradiso (2020). Neuroscience: Exploring the Brain, Enhanced Edition. Jones \& Bartlett Learning, LLC.

Benson, T. (1999). Blinded with science: American Indians, the Office of Indian Affairs, and the federal campaign against trachoma, 1924-1927. American Indian Culture and Research Journal 23(3), 119-142.

Billings, S. B., E. Chyn, and K. Haggag (2021, September). The Long-Run Effects of School Racial Diversity on Political Identity. American Economic Review: Insights 3(3), 267-84.

Blaney, P. H. (1986). Affect and memory: A review. Psychological Bulletin 99, 229-246.

Bliss, T. V. and T. Lømo (1973). Long-lasting potentiation of synaptic transmission in the dentate area of the anaesthetized rabbit following stimulation of the perforant path. The Journal of Physiology 232(2), 331-356.

Bordalo, P., N. Gennaioli, and A. Shleifer (2020). Memory, Attention, and Choice. Quarterly Journal of Economics 135(3), 1399-1442.

Botsch, M. and U. Malmendier (2018). Inflation Experiences and Contract Choice Evidence from Residential Mortgages. Working paper, UC-Berkeley.

Botsch, M. J. and U. Malmendier (2020). The Long Shadows of the Great Inflation: Evidence from Residential Mortgages.

Brachinger, H. W. (2008). A new index of perceived inflation: Assumptions, method, and application to Germany. Journal of Economic psychology 29(4), 433-457. 
Bray, M. (1982). Learning, Estimation, and the Stability of Rational Expectations Equilibria. Journal of Economic Theory 26, 318-339.

Brounen, D., P. Eichholtz, S. Staetmans, and M. Theebe (2014). Inflation Protection from Homeownership: Long-Run Evidence, 1814-2008. Real Estate Economics 42(3), $662-689$.

Bruine de Bruin, W., W. Vanderklaauw, J. S. Downs, B. Fischhoff, G. Topa, and O. Armantier (2010). Expectations of inflation: The role of demographic variables, expectation formation, and financial literacy. Journal of Consumer Affairs 44(2), 381-402.

Burton, H., A. Z. Snyder, and M. E. Raichle (2014). Resting state functional connectivity in early blind humans. Frontiers in systems neuroscience 8(51), 1-13.

Camargo, Braz, R. S. and T. Stinebrickner (2010). Interracial Friendships in College. Journal of Labor Economics 28(4), 861-892.

Canales, M. K., D. Weiner, M. Samos, N. S. Wampler, A. Cunha, and B. Geer (2011). Multi-generational perspectives on health, cancer, and biomedicine: Northeastern Native American perspectives shaped by mistrust. Journal of health care for the poor and underserved 22(3), 894-911.

Carrell, S., M. Hoekstra, and J. E. West (2019). The Impact of College Diversity on Behavior Toward Minorities. American Economic Journal: Economic Policy 11(4), $159-82$.

Carrell, S. E., M. E. Page, and J. E. West (2010, 08). Sex and Science: How Professor Gender Perpetuates the Gender Gap*. The Quarterly Journal of Economics 125(3), $1101-1144$.

Carter, S. S. (1991). Reflections Of An Affirmative Action Baby. BasicBooks.

Case, B. and S. M. Wachter (2011). Inflation and real estate investments. U of Penn, Inst for Law 85 Econ Research Paper 11-33.

Collin-Dufresne, P., M. Johannes, and L. A. Lochstoer (2017). Asset pricing when 'this time is different'. The Review of Financial Studies 30(2), 505-535.

D'Acunto, F., U. Malmendier, and M. Weber (2021, May). Gender Roles produce divergent economic expectations. Proceedings of the National Academy of Science 118(21), e2008534118.

D'Acunto, F., J. Ospina, U. Malmendier, and M. Weber (2021). Exposure to Grocery Prices and Inflation Expectations. Journal of Political Economy 129(5), 1615-1639.

Das, S., C. M. Kuhnen, and S. Nagel (2020). Socioeconomic status and macroeconomic expectations. The Review of Financial Studies 33(1), 395-432. 
Dee, T. S. (2007). Teachers and the Gender Gaps in Student Achievement. Journal of Human Resources 42(3), 528-554.

Doidge, N. (2007). The brain that changes itself: stories of personal triumph from the frontiers of brain science. Penguin.

Dolan, R. J. (2002). Emotions, Cognition, and Behavior. Science 298, 1191-1194.

Ehling, P., A. Graniero, and C. Heyerdahl-Larsen (2018). Asset prices and portfolio choice with learning from experience. The Review of Economic Studies 85(3), 1752-1780.

Einfeld, A. and D. Collins (2008). The relationships between service-learning, social justice, multicultural competence, and civic engagement. Journal of college student development 49(2), 95-109.

Engelbourg, S. (2001). Henry C. Wallich: A Third Generation Banker. Journal of the Economic \& Business Historical Society 19(1), 91-102.

Evans, G. W. and S. Honkapohja (2001). Learning and Expectations in Macroeconomics. Princeton, NJ: Princeton University Press.

Fama, E. F. and G. W. Schwert (1977). Asset returns and inflation. Journal of financial economics 5(2), 115-146.

Fluch, M., H. Stix, et al. (2005). Perceived Inflation in Austria-Extent, Explanations, Effects. Monetary Policy \&6 the Economy (3), 22-47.

Fodor, J. A. (1983). The Modularity of Mind: An Essay on Faculty Psychology. MIT Press.

Frey, U. and R. G. Morris (1997). Synaptic tagging and long-term potentiation. Nature $385(6616), 533-536$.

Frey, U. and R. G. Morris (1998). Synaptic tagging: implications for late maintenance of hippocampal long-term potentiation. Trends in neurosciences 21(5), 181-188.

Fuster, A., B. Hebert, and D. Laibson (2011). Natural Expectations, Macroeconomic Dynamics and Asset Pricing. In D. Acemoglu and M. Woodford (Eds.), NBER Macroeconomics Annual 2011. Chicago, IL: University of Chicago Press.

Fuster, A., D. Laibson, and B. Mendel (2010). Natural Expectations and Macroeconomic Fluctuations. Journal of Economic Perspectives 24, 67-84.

Georganas, S., P. J. Healy, and N. Li (2014). Frequency bias in consumemers' perceptions of inflation: An experimental study. European Economic Review 67, 144-158.

Gershenson, S., C. M. D. Hart, J. Hyman, C. Lindsay, and N. Papageorge (2021). The Long-Run Impacts of Same-Race Teachers. American Economic Journal: Economic Policy, forthcoming. 
Gordon, M. J. (1962). The investment, financing, and valuation of the corporation. RD Irwin.

Gärtner, H., M. Minnerop, P. Pieperhoff, A. Schleicher, K. Zilles, E. Altenmüller, and K. Amunts (2013). Brain morphometry shows effects of long-term musical practice in middle-aged keyboard players. Frontiers in Psychology 4 (636), 1-13.

Hertwig, R., G. Barron, E. U. Weber, and I. Erev (2004). Decisions from experience and the effect of rare events in risky choice. Psychological science 15(8), 534-539.

Isen, A. M., T. E. Shalker, M. Clark, and L. Karp (1978). Affect, accessibility of material in memory, and behavior: A cognitive loop? Journal of Personality and Social Psychology 36, 1-12.

Jonung, L. (1981). Perceived and expected rates of inflation in Sweden. The American Economic Review 71(5), 961-968.

Karmiloff-Smith, A. (2015). An alternative to domain-general or domain-specific frameworks for theorizing about human evolution and ontogenesis. AIMS Neuroscience 2(2), $91-104$.

Kaustia, M. and S. Knüpfer (2008). Do investors overweight personal experience? Evidence from IPO subscriptions. The Journal of Finance 63(6), 2679-2702.

Kofoed, M. S. and E. McGovney (2019). The Effect of Same Gender and Same-Race Role Models on Occupation Choice: Evidence from Randomly Assigned Mentors at West Point. Journal of Human Resources 54(2), 430467.

Kozlowski, J., L. Veldkamp, and V. Venkateswaran (2020). The tail that wags the economy: Beliefs and persistent stagnation. Journal of Political Economy 128(8), 28392879 .

LaBar, K. S. and R. Cabeza (2006). Cognitive neuroscience of emotional memory. Nature 7, 54-64.

Lavy, V. and E. Sand (2018). On the origins of gender gaps in human capital: Short- and long-term consequences of teachers' biases. Journal of Public Economics 167, 263-279.

Lawrence, J. (2000). The Indian health service and the sterilization of Native American women. American Indian Quarterly 24(3), 400-419.

Leombroni, M., M. Piazzesi, M. Schneider, and C. Rogers (2020). Inflation and the price of real assets. Working Paper, National Bureau of Economic Research.

Lim, J. and J. Meer (2017). The Impact of Teacher-Student Gender Matches: Random Assignment Evidence from South Korea. Journal of Human Resources 52(4), 979-997. 
Lim, J. and J. Meer (2021). Persistent Effects of Teacher-Student Gender Matches. Journal of Human Resources, forthcoming.

Liu, C. H., D. J. Hartzell, and M. E. Hoesli (1997). International evidence on real estate securities as an inflation hedge. Real Estate Economics 25(2), 193-221.

Low, H., C. Meghir, and L. Pistaferri (2010). Wage Risk and Employment Risk over the Life Cycle. American Economic Review 100(4), 1432-67.

Lusher, L., D. Campbell, and S. Carrell (2018, March). TAs Like Me: Racial Interactions between Graduate Teaching Assistants and Undergraduates. Journal of Public Economics 159, 203-224.

Maguire, E. A., K. Woollett, and H. J. Spiers (2006). London taxi drivers and bus drivers: A structural MRI and neuropsychological analysis. Hippocampus 16 (12), 1091-1101.

Malmendier, U. (2021). Experience Effects in Finance: Foundations, Applications, and Future Directions. Review of Finance, forthcoming.

Malmendier, U. and S. Nagel (2011). Depression Babies: Do Macroeconomic Experiences Affect Risk-Taking? Quarterly Journal of Economics 126(1), 373-416.

Malmendier, U. and S. Nagel (2016). Learning from inflation experiences. The Quarterly Journal of Economics 131(1), 53-87.

Malmendier, U., S. Nagel, and Z. Yan (2021). The making of hawks and doves. Journal of Monetary Economics 117, 19-42.

Malmendier, U., D. Pouzo, and V. Vanasco (2020a). Investor experiences and financial market dynamics. Journal of Financial Economics 136(3), 597-622.

Malmendier, U., D. Pouzo, and V. Vanasco (2020b). Investor experiences and international capital flows. Journal of International Economics 124, 103302.

Malmendier, U. and L. S. Shen (2020). Scarred Consumption. Working paper, UCBerkeley.

Malmendier, U. and A. Steiny (2018). Rent or Buy? The Role of Lifetime Experiences of Macroeconomic Shocks within and across Countries. Working paper, UC-Berkeley.

Marcet, A. and J. Sargent, Thomas (1989). Convergence of Least Squares Learning Mechanisms in Self-Referential Linear Stochastic Models. Journal of Economic Theory 48, $337-368$.

Muralidharan, K. and K. Sheth (2016). Bridging Education Gender Gaps in Developing Countries: The Role of Female Teachers. Journal of Human Resources 51(2), 269-97. 
Nagel, S. and Z. Xu (2019). Asset pricing with fading memory. Working Paper, National Bureau of Economic Research.

Perrin, A. J. and A. Gillis (2019). How college makes citizens: Higher education experiences and political engagement. Socius 5, 2378023119859708.

Perry, B. D., R. A. Pollard, T. L. Blakley, W. L. Baker, and D. Vigilante (1995). Childhood trauma, the neurobiology of adaptation, and "use-dependent" development of the brain: How "states" become "traits". Infant Mental Health Journal 16(4), 271-291.

Polipciuc, M., F. Coervers, and R. Montizaan (2021). Peers' Race in Adolescence and Voting Behavior. IZA Discussion Paper (14140).

Ranyard, R., F. Del Missier, N. Bonini, D. Duxbury, and B. Summers (2008). Perceptions and expectations of price changes and inflation: A review and conceptual framework. Journal of Economic Psychology 29(4), 378-400.

Rao, G. (2019). Familiarity Does Not Breed Contempt: Generosity, Discrimination and Diversity in Delhi Schools. American Economic Review 109(3), 774-809.

Richter-Levin, G. and I. Akirav (2003). Emotional Tagging of memory formation - in the search for neural mechanisms. Brain Research Reviews 43, 247-256.

Romer, C. D. and D. H. Romer (2008). The FOMC versus the Staff: Where Can Monetary Policymakers Add Value? The American Economic Review, 230-235.

Romer, D. H. (2010). A New Data Set on Monetary Policy: The Economic Forecasts of Individual Members of the FOMC. Journal of Money, Credit and Banking 42(5), 951-957.

Sargent, T. J. (1993). Bounded Rationality in Macroeconomics. Oxford, UK: Clarendon Press.

Sax, L. J., A. W. Astin, and J. Avalos (1999). Long-term effects of volunteerism during the undergraduate years. The review of higher education 22(2), 187-202.

Sharpe, M. J., H. M. Batchelor, L. E. Mueller, M. P. Gardner, and G. Schoenbaum (2021). Past experience shapes the neural circuits recruited for future learning. Nature Neuroscience, 1-10.

Shiller, R. J. (2005). Irrational Exuberance (second edition). Princeton, NJ: Princeton University Press.

Siminoff, L. A., C. J. Burant, and S. A. Ibrahim (2006). Racial disparities in preferences and perceptions regarding organ donation. Journal of general internal medicine 21(9), 995-1000. 
Spunt, R. P. and R. Adolphs (2017). A new look at domain specificity: insights from social neuroscience. Nature Reviews Neuroscience 18, 559-567.

Taylor, J. B. (1993). Discretion versus Policy Rules in Practice. Carnegie-Rochester Conference Series on Public Policy 39, 195-214.

Vlasenko, P. and S. R. Cunningham (2015). Capturing the Inflation that People Experience: The Everyday Price Index vs. the Consumer Price Index. American Institute for Economic Research Working Paper (004).

Wachter, J. A. and M. J. Kahana (2019). A retrieved-context theory of financial decisions. Working Paper, National Bureau of Economic Research.

Weber, E. U., U. Böckenholt, D. J. Hilton, and B. Wallace (1993). Determinants of diagnostic hypothesis generation: effects of information, base rates, and experience. Journal of Experimental Psychology: Learning, Memory, and Cognition 19(5), 1151.

Weingartner, H., H. Miller, and D. L. Murphy (1977). Mood-state-dependent retrieval of verbal associations. Journal of Abnormal Psychology 86, 276-284. 